\title{
LA PERSONA COMO AUTO-CONCIENCIA PERFORMANTE EN EL CENTRO DEL DEBATE BIOÉTICO. ANÁLISIS CRÍTICO DE LA POSTURA DE JOHN LOCKE
}

Bernard N. Schumacher*

RESUMEN: El autor analiza la definición de 'persona' de John Locke a la que se refieren numerosos filósofos de la bioética. Concentra su atención en una lectura crítica y precisa de un conocido pasaje, el cual aplica una transferencia de dicha definición del nivel de substancia a uno jurídico-moral; expone algunas contradicciónes lógicas internas de la definción de persona como auto-conciencia y conciencia moral, como la necesidad de incluir al cuerpo dentro de la definción para trascender el subjetivismo, los criterios de memoria auténtica que difieren de la cuasi-memoria y el estatus del ser humano ebrio o irreversiblemente incapaz de ejercitar la auto-conciencia en conexión con la teoría de los intereses. El autor concluye con una reflexión crítica acerca de las consecuencias éticas contemporáneas de la definición lockeana de persona performante.

rose

ABSTRACT: The author analyzes John Locke's definition of the "person" often referred to by many bioethics philosophers. He focuses on giving a critical and precise analysis of a known passage which utilizes that definition from a concrete to a judicial-moral level. In addition, he exposes some of its internal logical contradictions (self-consciousness and moral consciousness). For instance, the inclusion of the body into this definition in order to transcend subjectivism, the criteria of real memory which differs from quasi-memory, and the link between his theory of personal identity and inebriation and/or an incapacitated state where one is unable to use its self-consciousness. The author concludes with a critical reflection on the contemporary ethical consequences of Locke's definition of a performative person.

* Universidad de Friburgo. 
PALABRAS CLAVE: John Locke, persona, bioética, auto-conciencia, Teoría de los intereses, persona performante.

KEY WORDS: John Locke, person, bioethics, self-consciousness, social contract theory, performative person.

RECEPCIÓN: 10 de junio de 2009. APROBACIÓN: 14 de mayo de 2010. 


\section{LA PERSONA COMO AUTO-CONCIENCIA PERFORMANTE EN EL CENTRO DEL DEBATE BIOÉTICO. ANÁLISIS CRÍTICO DE LA POSTURA DE JOHN LOCKE*}

\section{La necesidad de formular una defi-} nición de persona humana se deja sentir hoy de manera particularmente aguda. El progreso de la medicina y de la biotecnología ha generado situaciones nuevas y, en consecuencia, numerosos problemas, referentes a la vida y a la muerte, en ocasiones difíciles de resolver. La investigación sobre el embrión y su clonación terapéutica o reproductiva, la posibilidad del eugenismo, ${ }^{1}$ el infanticidio o la eutanasia de seres humanos seniles o que padecen retraso mental severo, o incluso la definición misma de muerte ${ }^{2}$ (y lo que de ella se deriva en lo tocante al transplante de órganos), se han convertido, desde hace algunos años, en objeto de intensos debates. Estos diferentes problemas éticos remiten, entre otras cosas, a una interrogación fundamental que consiste en

* Traducción del francés de Mauricio López Noriega. El adjetivo performante del original es ambiguo: hace referencia a "excelentes resultados prácticos", a lo "muy eficiente" o "potente"; en fin, a algo de "muy altas calidades técnicas" o "muy competente". He preferido mantenerlo sin traducción, pero destacándolo en cursivas.

${ }^{1}$ La posibilidad del eugenismo es objeto de una intensa controversia, como se ve, por ejemplo, a propósito de la reciente obra de Jürgen Habermas, L'avenir de la nature humaine. Vers un eugénisme libéral?, 2002, Paris, Gallimard, traducido del alemán por Christian Bouchindhomme [Die Zukunft der menschlichen Natur. Auf dem Weg zu einer liberalen Eugenik?, 2001, Frankfurt am Main, Suhrkamp]. Cabe aclarar que eugenismo, a diferencia de eugenesia, es una doctrina de perfeccionamiento de una raza ( $N$. del T.).

${ }^{2}$ Ver Bernard N. Schumacher, Confrontations avec la mort. La philosophie contemporaine et la question de la mort, 2005, Paris, Cerf, p. 27 ss. 
BERNARD SCHUMACHER

preguntarse qué criterio define a la persona humana (¿qué es una persona?) y si dicho criterio es consistente (¿todos los seres humanos son personas?). Dado que, frecuentemente, los juicios de la bioética varían por la concepción que se tiene de la persona humana, y por el aumento de los problemas éticos debatidos, la filosofía debe dar hoy cumplimiento a su tarea. Uno de los papeles de la filosofía es contribuir a tal debate en nuestras sociedades. ${ }^{3}$

La reflexión antropológica subyacente a los debates bioéticos actuales descansa sobre un a priori aceptado por la mayor parte de los facultativos, incluso si algunos lo califican de "estúpido": 4 la persona humana está provista de derechos y, en particular, del derecho fundamental a la vida, así como de una dignidad intrínseca que exige que la persona sea tratada, siguiendo el segundo imperativo categórico de Emmanuel Kant, como un fin en sí y jamás como un simple medio.

La persona humana no tiene precio, es decir, escapa a toda instrumentalización, como lo pone de manifiesto, de nuevo, el reciente informe del Consejo Bioético del presidente de los Estados Unidos (Human Dignity and Bioethics). ${ }^{5}$ En adelante, en la medida en que un recién nacido, un ser humano que padece un retraso mental profundo o demencia grave, es considerado como persona, tiene el derecho a vivir. El problema se plantea cuando el valor de dos personas con su propia dignidad entra en conflicto. En este caso, matar a una persona sería un acto intrínsecamente malo desde el punto de vista ético, independientemente de las circunstancias, de la intención o de criterios utilitaristas. Por el contrario, si un recién nacido, un ser humano que padece un retraso mental profundo o demencia grave, no debiera ser considerado como persona -posición sostenida en las últimas décadas por un número creciente de

${ }^{3}$ Ver François-Xavier Putallaz y Bernard N. Schumacher (ed.), L'humain et la personne, 2008, Paris, Cerf, con un prefacio de Pascal Couchepin, presidente de la Confederación Helvética.

${ }^{4}$ Ver Steven Pinker, "The Stupidity of Dignity”, en The New Republic, 28 de mayo de 2008. Véase también Peter Singer, para quien la "dignidad humana" no significa sino una "bella expresión" para "quienes quedaron cortos de argumentos" (Applied Ethics, 1986, Oxford, Oxford University Press, pp. 215-28, ("dignity of human mankind", "fine phrases are the last resource of those who have run out of arguments", p. 228).

${ }^{5}$ Ver Consejo Presidencial de Bioética (E. U.), Human Dignity and Bioethics: Essays Commissioned by the President's Council on Bioethics, 2008, Washington D.C., US Independent Agencies and Commissions. 
filósofos que siguen a Peter Singer, Michael Tooley, Tristram Engelhardt o incluso Jeff McMahan, ${ }^{6}$ por nombrar sólo a algunos-, la eutanasia no constituiría un homicidio. Dichos filósofos se niegan a utilizar los términos 'persona' y 'ser humano' de manera intercambiable. Proponen definir al ser humano a partir de criterios estrictamente biológicos. El ser humano sería equivalente a 'miembro de la especie homo sapiens'. La persona se definiría, en cambio, por el ejercicio concreto de un cierto número de propiedades, en particular la racionalidad y la auto-conciencia a través del tiempo, así como de la moralidad y el hecho de ser responsable de sus acciones. De esta manera, según dichos filósofos, el ser humano no es, necesariamente, una persona por su sola pertenencia a la especie humana, sino en la medida en que sea un sujeto que ejerce concretamente, es decir, empíricamente, la racionalidad y la autoconciencia, por una lado, y por el otro, sus acciones morales.

Uno de los autores más reconocidos en materia de bioética, Tristram Engelhardt, precisa:

Lo que distingue a las personas es su capacidad [en el sentido de ser en acto o del ejercicio] de ser auto-conscientes y racionales, y

${ }^{6}$ Ver, entre otros, Bernard Baertschi, La valeur de la vie humaine et l'intégrité de la personne, 1995, Paris, Presses Universitaires de France, pp. 71 ss. y 157 ss.; Dieter Birnbacher, "Das Dilemma des Personbegriffs", en Peter Strasser y Edgar Starz (eds.), Personsein aus bioethischer Sicht, 1997, Stuttgart, Franz Steiner, pp. 9-25; Peter Carruthers, Introducing Persons. Theories and Arguments in the Philosophy of Mind, 1986, London, Croom Helm, pp. 227 ss.; Stéphane Chauvier, Qu'est-ce qu'une personne?, 2003, Paris, Vrin; Tristram H. Engelhardt Jr., The Foundations of Bioethics, 1996, Oxford, Oxford University Press, segunda edición, pp. 135 ss. y 239 ss.; Norbert Hoerster, Abtreibung im säkularen Staat, 1991, Frankfurt am Main, Suhrkamp; Jonathan Glover, Causing Death and Saving Lives, (1977) 1987, Harmondsworth, Middlesex, England, Penguin Books; Jeff McMahan, The Ethics of Killing. Problems at the Margins of Life, 2002, Oxford, Oxford University Press; Roland Puccetti, "The Life of a Person", en William B. Bondeson, Tristram H. Engelhardt, Stuart F. Spicker y Daniel H. Winship (eds.), Abortion and the Status of the Fetus, 1983, Dordrecht, Reidel, pp. 169-82 y 172 ss.; Peter Singer, Questions d'éthique pratique, 1997, Paris, Bayard, pp. 91 ss. [traducido del inglés por Max Marcuzzi, Practical Ethics, 1993, Cambridge, Cambridge University Press, segunda edición, pp. 85 ss.], p. 117 ss.; Michael Tooley, "Abortion and Infanticide", en Philosophy and Public Affairs, 1972 (2), núm. 1, pp. 37-65; y "Personhood”, en Helga Kuhse y Peter Singer (eds.), A Companion to Bioethics, 1988, Blackwell, Oxford, pp. 117-26; Abortion and Infanticide, 1983, Oxford, Clarendon Press; Mary Anne Warren, "On the Moral and Legal Status of Abortion", en The Monist, 1973 (57), pp. 43-61; Robert N. Wennberg, Life in the Balance. Exploring the Abortion Controversy, 1985, Grand Rapids (MI), Eerdmans, pp. 31 ss. 
BERNARD SCHUMACHER

de preocuparse de saber si merecen censura o alabanza $[\ldots]$ no todos los seres humanos son personas. No todos los seres humanos son auto-conscientes, racionales y capaces de concebir la posibilidad de censura o alabanza. Los fetos, los recién nacidos, los individuos que sufren retraso mental profundo y aquellos que están sumidos en coma irreversible [y se podría añadir a los individuos seniles, siguiendo a algunos autores] proporcionan ejemplos de seres humanos que no son personas. Son miembros de la especie humana pero no tienen en, ni por ellos mismos, un lugar en la comunidad moral laica. ${ }^{7}$

Nuestro autor sostiene, como lo hizo ya Peter Singer, uno de los filósofos cuyas ideas tienen mayor impacto en la práctica de la medicina, que "no todos los seres humanos son iguales". ${ }^{8}$ Mientras que una vida humana en el sentido biológico del término "tiene poco valor moral en sí”, la persona humana posee derechos y dignidad. ${ }^{9}$ El filósofo australiano no podría haber sido más preciso que cuando escribe:

La vida de un ser consciente de sí mismo, capaz de tener pensamientos abstractos, de planear el futuro, de producir complejos actos de comunicación, etc. [es decir, una persona] tiene más valor que la vida de un ser al que faltan sus capacidades [a saber, un ser humano]. ${ }^{10}$

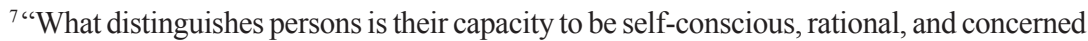
with worthiness of blame and praise. [...] On the other hand, not all humans are persons. Not all humans are self-conscious, rational, and able to conceive of the possibility of blaming and praising. Fetuses, infants, the profoundly mentally retarded, and the hopelessly comatose provide examples of human nonpersons. They are members of the human species but do not in and of themselves have standing in the secular moral community", Tristram Engelhardt Jr., The Foundations of Bioethics, op. cit., pp. 138-9. Más adelante, Engelhardt añade a los seniles entre las no personas (p. 239).

${ }^{8}$ Ibidem, p. 135: "Not all humans are equal".

9 "Insofar as we identify persons with moral agents, we exclude from the range of the concept of person those entities which are not self-conscious. Which is to say, only those beings are unqualified bearers of rights and duties who can both claim to be acknowledged as having a dignity beyond a value (i.e., as being ends in themselves), and can be responsible for their actions. [...] It is only respect for persons in this strict sense that cannot be violated without contradicting the idea of a moral order in the sense of living with others on the basis of mutual respect." Idem. "Medicine and the Concept of Person" en Michael F. Goodman (ed.), What is a Person?, 1988, Clifton (N.J.), Humana Press, pp. 169-84, 172-3.

${ }^{10}$ Peter Singer, Questions d'éthique pratique, p. 69: "the life of a self-aware being, capable of abstract thought, of planning for the future, of complex acts of communication, and so on [une personne], is more valuable than the life of a being without these capacities [un être humain]", p. 61. Ver también, p. 79 [73]. 
Consecuentemente, los seres humanos no son iguales entre sí. Sólo aquél que es una persona posee un "serio derecho a la vida", en palabras de Michael Tooley, ${ }^{11}$ quien afirma:

Tener derecho a la vida presupone que uno sea capaz de desear seguir existiendo como sujeto de experiencias y otros estados mentales. Ello presupone, a su vez, tanto que uno tenga el concepto de tal entidad continuante como que uno crea que es un sí mismo tal entidad. Así, una entidad desprovista de tal auto-conciencia como sujeto continuante de estados mentales no tiene derecho a la vida. ${ }^{12}$

Los filósofos que, en el ámbito de la actual discusión bioética, defienden la distinción entre 'ser humano' y 'persona' se refieren, generalmente, a la definición lockeana de persona 'desubstancializada', al invocar, según algunos, la concepción kantiana de la persona moral como sujeto autónomo en el origen de las acciones que le pueden ser imputadas y que expresan concretamente intereses -idea que, por otro lado, se encuentra también en la pluma de John Locke. A pesar de la preponderancia de la definición lockeana de persona en el debate bioético actual, la inmensa mayoría de los protagonistas de dicha discusión omiten analizar, precisamente, la posición del filósofo inglés y sus presupuestos. Tal es el objeto de esta contribución, que hará resurgir ciertas contradicciones argumentativas inherentes.

John Locke, quien junto con René Descartes y Gottfried Wilhelm von Leibniz, origina la constitución moderna del sujeto, adopta una visión antropológica que se puede calificar de revolucionaria, en la medida en que comienza por considerar a la persona independientemente de toda substancia material o pensante. La cuestión central consiste en "saber aquello que hace [que se trata de] la misma persona". ${ }^{13}$ En cuanto

${ }^{11}$ Michael Tooley, "Abortion and Infanticide", op. cit., p. 37: "A serious right to life".

${ }^{12} \mathrm{Ibid}$, p. 49: "having a right to life presupposes that one is capable of desiring to continue existing as a subject of experiences and other mental states. This in turn presupposes both that one has the concept of such a continuing entity and that one believes that one is oneself such an entity. So an entity that lacks such a consciousness of itself as a continuing subject of mental states does not have a right to life."

${ }^{13}$ John Locke, "Identité et différence" en Essai philosophique concernant l'entendement humain, libro II, capítulo 27, pp. 133-81, en Identité et différence. L'invention de la conscience, 
BERNARD SCHUMACHER

a saber "si es la misma substancia idéntica la que piensa siempre en la misma persona [...] [esta cuestión] no tiene importancia alguna". ${ }^{14} \mathrm{El}$ filósofo inglés, que rompe así con toda una tradición, precisa: "es falso pensar que la unidad de la substancia incluye todas las especies de identidad, o la determina en todos los casos". ${ }^{15}$ La definición de persona no se funda ya sobre el yo-substancia, sino sobre la cognición, es decir, en el ejercicio performante de la conciencia, o dicho de otro modo, sobre el yo-conciencia. Esta definición rompe la adecuación cartesiana entre la res cogitans y el pensamiento no actual. Según Locke, tal adecuación implica "de manera gratuita y sin razón"16 que no es necesario ser consciente de pensar para ser persona, de modo que, por ejemplo, un ser humano ebrio o profundamente dormido podría ser calificado como persona. El término 'conciencia' reviste, sin embargo, un significado doble: por una parte, puede significar la actividad de hacerse cargo de sí mismo en tanto que yo: dicho de otra manera, autoconciencia; por otra, la conciencia llamada moral, en consideración de las acciones libres y responsables.

Locke no se refiere solamente al primer sentido antedicho, como parecen pensarlo buen número de filósofos bioéticos contemporáneos, sino también, y antes que nada, al segundo sentido que está al principio del primero. En efecto, la proposición antropológica lockeana es una respuesta a un problema teológico y, más particularmente, a una consideración ética: el juicio divino de las acciones libres y responsables de la persona durante su vida. De esta manera, y antes que nada, el término 'persona' es un "término jurídico", ${ }^{17}$ es decir, que no tiene sentido más

1998, Paris, Seuil, presentación, traducción y comentario de Etienne Balibar, edición bilingüe, $\S 10,151$ ["The question being what makes the same person", 150].

${ }^{14}$ John Locke, "Identité et différence", § 10, 151 ["whether it be the same identical substance, which always thinks in the same person, which in this case matters not at all", p. 150].

${ }^{15} \mathrm{Idem}, \S 7,143$ : "It is not therefore unity of substance that comprehends all sorts of identity, or will determine it in every case", 142.

${ }^{16}$ John Locke, Essai philosophique concernant l'entendement humain, 1989, Paris, Vrin, trad. de Pierre Coste, ed. de Emilienne Naert, libro II, capítulo 1, § 10, 64: "is to be, what is in Question, and not to prove it by Reason", 109.

${ }^{17}$ John Locke, "Identité et différence”, § 26, p. 177: “a forensic term”, p. 176. 
que para un sujeto moral que se imputa sus propias acciones y que, al rendir cuentas ante su propia conciencia, Dios y la comunidad, es reconocido por la misma como el autor de sus propias acciones y, por tanto, como responsable. El giro revolucionario lockeano se caracteriza, así, por una comprensión de la persona en el marco específico de un tribunal de derecho, de donde la reducción de la persona a su capacidad de imputarse actos morales. El filósofo inglés reduce la persona a su papel social y moral, negando implícitamente, por lo mismo, dicho estatus a todos aquellos que no ejercen actos morales empíricamente constatables. Este cambio de paradigma, suscrito por un creciente número de filósofos bioéticos, los conduce a sostener una desigualdad fundamental en el trato entre seres humanos, al conceder dignidad únicamente a los sujetos morales, esto es, a las personas que ejercitan la auto-conciencia y la conciencia moral.

Según Locke, cuando se ha juzgado una acción moral personal, la justicia del juicio requiere no solamente de la presencia de una persona llamada moral, sino también de su corolario, la identidad de dicha persona a través del tiempo, a saber, entre el momento en el que realiza una acción moral y el instante del juicio de la misma acción. La persona se define desde ese momento por la performance de la conciencia, en los dos sentidos del término: por una parte, la actividad cognitiva de reunir los objetos de conocimiento en un yo y, por otra, por la acción moral libre y responsable, a saber, por su dimensión jurídica. Locke sienta las bases de la concepción moderna de persona al vincular el sujeto llamado psicológico al sujeto llamado moral, vínculo que, sin embargo, no se sitúa a nivel de la substancia, sino del ejercicio de facultades empíricamente observables, en la medida en que el sujeto pueda conscientemente apropiarse o imputarse acciones. De ello, se deriva una distinción entre 'ser humano' y 'persona', dado que la pertenencia a la especie humana ya no es criterio suficiente para ser persona humana. A fin de ser considerado como persona, disponiendo entre otros de un serio derecho a la vida, hace falta necesariamente ser -en el sentido del ejercicio concreto- un sujeto moral auto-consciente. Una diferenciación tal, ciertamente suscitó reacciones de oposición entre los contem- 
BERNARD SCHUMACHER

poráneos de Locke, ${ }^{18}$ pero limitadas a una discusión teórica sobre el criterio de la identidad personal (por otro lado, esta cuestión favorece una fuerte renovación del interés de la filosofía analítica desde hace algunas décadas). ${ }^{19}$ Hará falta esperar tres siglos para que la distinción y la reducción antropológica aplicada por el filósofo inglés tuviera importantes consecuencias éticas.

Me propongo examinar, en un primer momento, el criterio por medio del cual Locke determina la identidad del ser humano a través del tiempo. Enseguida, estudiaré su definición de persona como auto-conciencia y mostraré ciertas contradicciones internas, especialmente la necesidad que siente de reinsertar la corporeidad en su definición, a fin de trascender el subjetivismo. Concluiré con una reflexión sobre las consecuencias éticas de la definición lockeana de persona, que se puede calificar de performante y que está en la base de cierta idea contemporánea de persona.

\section{El juicio de las acciones morales en el centro de la definición de la persona}

16 El filósofo inglés precisa, desde las primeras páginas de su Ensayo sobre el entendimiento humano, publicado en 1690, que el fin de sus reflexiones, a lo largo de las 700 páginas, consiste en "examinar las diferentes Facultades de conocer que se encuentran en el Hombre" y

${ }^{18}$ Ver Thomas Beconsall, The Doctrine of a General Resurrection: Wherein the Identity of the Rising Body is asserted, against the Socinians and Scepticks, 1697, Oxford, pp. 14-5. John Sergeant, Solid Philosophy Asserted, Against the Fancies of the Ideists: Or, the Method to Science Farther Illustrated. With Reflexions on Mr. Locke's Essay concerning Human Understanding, 1696, London, p. 262.

${ }^{19}$ Ver Henry E. Allison, "Locke's Theory of Personal Identity: A Re-examination” en Ian C. Tipton (ed.), Locke on Human Understanding. Selected Essays, 1977, Oxford, Oxford University Press, pp. 105-22; James Baillie, "Recent Work on Personal Identity", en Philosophical Books, 1993, 34, pp. 193-206; Derek Parfit, Reason and Persons, 1984, Oxford, Clarendon Press; Sidney Shoemaker, Self-Knowledge and Self-Identity, 1963, London, Ithaca, pp. 45-50, 143-9; David Wiggins, Sameness and Substance Renewed, 2001, Cambridge, Cambridge University Press; Bernard Williams, "Personal Identity and Individuation", en Problems of the Self. Philosophical Papers 1956-1972, 1973, 1995, Cambridge, Cambridge University Press, pp. 1-18. 
que lo elevan "por encima de todos los seres sensibles", es decir, que le otorgan una "superioridad" sobre ellos. ${ }^{20}$ La razón de tal supremacía no tiene su origen en la substancia pensante comúnmente denominada "alma", como lo sostiene una parte de la tradición filosófica occidental, sino en la performance de las actividades del entendimiento. Locke trata esta idea central, relativa a la definición de persona y a su identidad a través del tiempo, en el capítulo veintisiete, titulado "Identidad y diferencia", que redacta a sugerencia de su amigo William Molyneux durante la primavera y verano de 1693, y que publica al año siguiente en la segunda edición de su obra. La escritura de las páginas centrales fue motivada por un rechazo al dualismo cartesiano pero, sobre todo, por el deseo de justificarse ante las objeciones de los teólogos. ${ }^{21}$ Éstos, en efecto, se inquietaban por que la puesta entre paréntesis de la sustancia inmaterial del alma humana de la definición de persona no condujera a la supresión de la inmortalidad personal. La reflexión lockeana sobre la persona no es una especulación puramente teórica, sino que responde a una cuestión ética fundamental, ligada a un problema teológico, como había sido ya el caso, por ejemplo, de Boecio con respecto a la cuestión cristológica. ${ }^{22}$

¿Cuál es la dificultad que enfrenta el filósofo inglés? No se trata, en absoluto, del archè de la persona, sino más bien del eschaton, es decir, del fin último del destino personal después de la muerte. La fe cristiana afirma que la persona occisa comparece delante de un tribunal donde Dios juzga las acciones morales realizadas durante su vida. Locke no propone ningún argumento filosófico para demostrar, o incluso cali-

${ }^{20}$ John Locke, Essai philosophique concernant l'entendement humain, prefacio, 2 y 1: "to consider the discerning Faculties of a man"; "that sets Man above the rest of sensible Beings"; "Dominion", An Essay Concerning Human Understanding, editado por Peter H. Nidditch, 1975, Oxford, Clarendon Press, libro I, capítulo 1, pp. 43-4 y 43.

${ }^{21}$ Lo mismo para René Descartes, quien precisa en una carta a los decanos de la Facultad de Teología de París que su intención era demmostrar con ayuda de la razón la inmortalidad del alma y la existencia de Dios. Ver René Descartes, "A Messieurs les doyens et docteurs" en Méditations métaphysiques, 2004, Paris, Presses Universitaires de France, $6^{\text {ta }}$ edición, 5ss. (AT, IX, 4ss.).

${ }^{22}$ Ver Boèce, Traité sur la personne et les deux natures du Christ contre Eutychès et Nestorius (Contra Eutychen et Nestorium) en Courts traités de théologie. Opuscula sacra, 1991, Paris, Cerf, colección 'Sagesses chrétiennes', textos traducidos, presentados y anotados por Hélène Merle. En torno a las disputas teológicas del siglo XVII, v. Philip Dixon, 'Nice and Hot Disputes'. The Doctrine of the Trinity in the Seventeenth Century, 2003, London, T \& T Clark. 
BERNARD SCHUMACHER

ficar de probable, la existencia de un jucio final, pues este mismo escapa por principio a toda demostración filosófica. Dada a priori, la realidad de dicha existencia se funda en un acto de fe en un Dios bueno que se revela a los hombres, como, por otro lado, había propuesto Platón al referirse a los mitos que describían la vida después de la muerte. ${ }^{23} \mathrm{Al}$ creer en la veracidad de la revelación cristiana por medio de un acto de fe personal, Locke invoca explícitamente la palabra revelada por intermedio de San Pablo, quien sostiene que en el día del Juicio final cada uno "será recompensado conforme a sus actos, los secretos de todos los corazones serán puestos al desnudo". ${ }^{24} \mathrm{Si}$ bien la existencia de un juicio divino es inaccesible a la sola razón, ello no quiere decir que también lo sean las implicaciones lógicas de este justo juicio. Se pueden enunciar tres.

En primer lugar, Dios debe ser fundamentalmente bueno y justo. No sabría ser engañoso o maligno, obteniendo placer en recompensar o culpar a una persona por una acción que no hubiera realizado. El filósofo inglés supone verdadera a priori a la bondad divina, por medio de un acto de fe en la revelación divina. En segundo, la persona juzgada post mortem debe ser idéntica a la persona ante mortem para que la recompensa o el castigo divinos, en atención a las acciones morales, sea justo. En efecto, la persona post mortem debe estar en condiciones de que se le imputen sus acciones morales realizadas ante mortem. En tercer lugar, la persona debe ser libre y responsable, es decir, consciente de la moralidad y del alcance de sus actos, lo cual implica el ejercicio de un juicio racional y de una auto-conciencia. Recompensar o castigar a una persona total o momentáneamente determinada en su acción, o bien, privada de conciencia moral a nivel jurídico, comportaría una profunda injusticia.

Los dos significados del término 'conciencia' que hemos mencionado más arriba -la auto-conciencia y la conciencia moral-son pues-

${ }^{23}$ Ver Platon, Phédon, 1991, Paris, Garnier Flammarion, traducido por Monique Dixsaut. Sobre la interpretación de los mitos platónicos, v. también Josef Pieper, Über die platonischen Mythen dans Werke in acht Bänden, 2002, Hamburg, Felix Meiner, editado por Berthold Wald, Tomo 1, 332-74.

${ }^{24}$ John Locke, "Identité et différence", § 26, 179: "every one shall receive according to his doings, the secrets of all Hearts shall be laid open" 178. Ver Epístola a los Romanos, 2, 6. 
tos en evidencia claramente en la definición lockeana de persona, que funda una cierta corriente de la antropología bioética contemporánea. Si un ser humano debiera ser privado del ejercicio, a la vez de la auto-conciencia y de la conciencia moral, que lo hacen "suceptible de reconocer una ley" y "cuidadoso y responsable de sus actos pasados", ${ }^{25}$ todo veredicto de un juicio divino -y por extensión, del juicio humano de la Ciudad-, sería injustificado y aleatorio. ${ }^{26}$ Por otro lado, la persona que será juzgada por Dios por acciones morales que no hubiese realizado, estaría, según anota Locke:

Destinado a la felicidad o a la desdicha desde el nacimiento [por el solo hecho de existir], sin haber hecho nada. Pues, si suponemos que un hombre pudiera ser castigado ahora por algo que hubiera hecho en otra vida, en la cual ninguna conciencia le hubiese sido dada, ¿qué diferencia habría entre tal castigo y el hecho de haber sido creado para la desdicha? ${ }^{27}$

Para que un juicio moral sea considerado justo, es necesario proponer criterios racionales que permitan definir a la persona, y más particularmente, determinar su continuidad a través del tiempo. Si tal empresa se comprueba imposible, el castigo o la recompensa por las acciones morales pasadas estaría vaciado de su sentido original; dicho de otra manera, sería relativo a la intención del juez. A partir de aquí, el filósofo inglés se ve forzado a precisar, desde un primer momento, el concepto de identidad en general y, más específicamente, el de ser humano, antes de abordar el concepto de identidad de la persona.

${ }^{25}$ John Locke, "Identité et différence", § 26, 177: "capable of law"; "concerned and accountable, owns and imputes to it self past actions", 176.

${ }^{26} \mathrm{Idem}, \S 26,179$ : "El veredicto debe ser justificado por la conciencia que todas las personas deben tener, en cuanto ellas mismas sean mismas quienes han cometido precisamente dichos actos y merecen, así, ser castigados por ellos, sea cual fuere el cuerpo en el cual se muestren o las sustancias a las cuales dicha conciencia esté ligada" ["The sentence shall be justified by the consciousness all persons shall have, that they themselves in what bodies soever they appear, or what substances soever that consciousness adheres to, are the same, that committed those actions, and deserve that punishement for them", 178].

${ }^{27} \mathrm{Idem}, \S 26,177$ : “As to be made happy or miserable in its first being, without any demerit at all. For supposing a man punished now, for what he had done in another life, whereof he could be made to have no consciousness at all, what difference is there between that punishment, and being created miserable?", 176. 


\section{El principio de la identidad del ser humano}

El punto de partida de la definición lockeana de la identidad humana y de la identidad personal reside en la distinción que aplica entre la esencia real, por una parte, y la esencia nominal, por la otra. Después de haber descartado a priori la concepción aristotélica de la existencia real como una especie en sentido universal, Locke opta por una segunda concepción -“mucho más razonable", según él- de la esencia real, como el fundamento subyacente a las diferentes características que definen a un individuo particular.

La otra opinión, que es mucho más razonable, es la de quienes reconocen que todas las cosas naturales tienen una cierta constitución real, pero desconocida, de sus partes insensibles, de donde fluyen las cualidades sensibles que nos sirven para distinguir las cosas, una de la otra, según tengamos ocasión de distinguirlas en ciertas clases, bajo sus denominaciones comunes. ${ }^{28}$

Si bien una esencia real estaría presente en el seno de la naturaleza misma de las cosas individuales, es decir, que existe temporalmente antes de la formación de una esencia nominal que depende de la esencia real, ${ }^{29}$ una esencia tal escapa, sin embargo, al entendimiento humano. Éste capta las diversas cualidades comunes observables - podría añadirse 'empíricamente'- de un cierto número de individuos a partir de los

${ }^{28}$ John Locke, Essai philosophique concernant l'entendement humain, III, 3, § 17, 335-6: "The other, and more rational Opinion [concerning essences], is of those, who look on all natural Things to have a real, but unknown Constitution of their insensible Parts, from which flow those sensible Qualities, which serve us to distinguish them one from another, according as we have Occasion to rank them into sorts, under common Denominations." 417-8. Ibidem, III, $3, \S 15,334$ : "And thus the real internal, but generally in Substances, unknown Constitution of Things, whereon their discoverable Qualities depend, may be called their Essence. [...] And in this sense it is still used, when we speak of the Essence of particular things, without giving them any Name." 417.

${ }^{29}$ V. idem, III, 6, § 2, 353: "yo la nombro por lo tanto Esencia nominal, para distinguirla de la constitución real de las Substancias, de donde dependen todas las ideas que entran dentro de la Esencia nominal" ["I call it by a peculiar name, the nominal Essence, to distinguish it from that real Constitution of Substances, upon which depends this nominal Essence." 439]. 


\section{cuales construye libremente la esencia nominal. ${ }^{30}$ Las propiedades de} una cosa no se buscan a nivel de los individuos, sino de la especie, que es de la competencia del entendimiento. ${ }^{31}$ El nominalismo lockeano sostiene que sólo los individuos existen y que lo universal es del orden de la creación del entendimiento, que pragmáticamente elige clasificar las cosas según aquello que corresponda mejor a nuestras necesidades. ${ }^{32}$

30 "En lugar de designar la constitución real de las cosas, casi ha sido enteramente aplicado a la constitución artificial del Género y de la Especie. Es verdad que se supone, ordinariamente, una constitución real de la especie de cada cosa, y está fuera de duda que debe haber alguna constitución real, de donde cada conjunto de ideas simples coexistentes deba depender. Pero, como es evidente que las cosas no están ordenadas en Clases o Especies bajo ciertos nombres que, en tanto que convienen con ciertas ideas abstractas a las que hemos ligado dichos nombres, la esencia de cada Género o Especie viene así a no ser otra cosas que la idea abstracta, significada por el nombre general o específico. Y nosotros encontramos que es esto lo que lleva la palabra de esencia según el uso más ordinario que se ha hecho [...] esence nominal." John Locke, Essai philosophique concernant l'entendement humain, III, $3, \S 15,334-5$ ["And instead of the real Constitution of things, has been almost wholly applied to the articifial Constitution of Genus and Species, the Word Essence has almost lost its primary signification; and instead of the real Constitution of things, has been almost wholly applied to the artificial Constitution of Genus and Species. 'This true, there is ordinarily supposed a real Constitution of the sorts of Things; and 'tis past doubt, there must be some real Constitution, on which any Collection of simple Ideas co-existing, must depend. But it being evident, that Things are ranked under Names into sorts or Species, only as they agree to certain abstract Ideas, to which we have annexed those Names, the Essence of each Genus, or Sort, comes to be nothing but that abstract Idea, which the General, or Sortal (if I may have leave so to call it from Sort, as I do General from Genus, ) Name stands for. And this we shall find to be that, which the Word Essence imports, in its most familiar use. [...] Nominal Essence." 417]. $V$. ibidem, III, 3, § 6-8, 329-30 [410-2] et III, 6, § 37, 373 [462].

${ }^{31}$ V. Essai philosophique concernant..., op. cit., III, 6, § 6, 356 [442].

${ }^{32} \mathrm{~V}$. idem, III, 3, § 6, 329: "Pues todo lo que existe, siendo particular, ¿cómo es que tenemos términos generales, y de dónde sacamos dichas naturalezas universales que tales términos significan? Las palabras devienen generales cuando son instituidas como signos de ideas generales; y las ideas devienen generales cuando se separa las circunstancias de tiempo, de lugar y de toda idea que pueda determinarlas a tal o cual existencia particular. Por esta fuerza de abstracción se vuelven capaces de representar igualmente múltiples cosas individuales, en donde cada una está en sí misma conforme a dicha idea abstracta; de esta especie de cosas, es como se hable." " "For since all things that exist are only particulars, how come we by general Terms, or where find we those general Natures they are supposed to stand for? Words become general, by being made the signs of general Ideas: and Ideas become general, by separating from them the circumstances of Time, and Place, and any other Ideas, that may determine them to this or that particular Existence. By this way of abstraction they are made capable of representing more Individuals than one; each of which, having in it a conformity to that abstract Idea, is (as we call it) of that sort." 410]. 
BERNARD SCHUMACHER

La célebre distinción lockeana entre 'ser humano' y 'persona' tiene su origen en el rechazo de la concepción aristotélica de la esencia, según la cual, la esencia real de una cosa individual expresaría, igualmente, la universal. Esta distinción tiene también una intención práctica en la medida en que permite resolver algunos casos raros; en efecto, inmediatamente después del pasaje citado líneas arriba, el filósofo inglés precisa que la distinción nominalista entre esencia real y esencia nominal permite resolver la cuestión del estatus de los “imbéciles" -el equivalente, en lenguaje contemporáneo, sería el individuo que padece de un retraso mental profundo o que se encuentre en un caso similar. Los "imbéciles" parecen radicalmente diferentes, desde el punto de vista de las propiedades de la persona, la cual se define-como veremos-por la auto-conciencia y la conciencia moral. Locke no puede comprender cómo una misma esencia real -aquí el ser humano-podría expresarse en propiedades distintas -a saber, la ausencia, respectivamente, de la presencia de la racionalidad y de la moralidad-, empíricamente observables, siendo por completo idénticas en cuanto a la clase de cosa que son.

El nacimiento de imbéciles y de otros extraños frutos en los alumbramientos comporta dificultades que no son posibles de conciliar con esta hipótesis [se refiere aquí a la concepción aristotélica de la esencia], debido a que es del todo imposible que dos cosas que participan exactamente de la misma esencia real tengan propiedades diferentes; al igual que es imposible que dos figuras participen de la misma esencia real de un Círculo tengan propiedades diferentes. ${ }^{33}$

Además de su negativa a reconocer lo universal en lo singular, aquí Locke afirma a priori que una cosa no puede pertenecer a una especie a menos que las propiedades de dicha cosa sean constatables empíricamente -es decir, que sean concretamente ejercidas. Examinaré en detalle este a priori reduccionista sobre el cual se basan también los filósofos bioeticistas mencionados.

${ }^{33}$ Idem, III, 3, § 17, 335: "The frequent productions [...] of Changelings, and other strange Issues of humane Birth, carry with them difficulties, not possible to consist with this Hypothesis: Since it is as impossible, that two Things, partaking exactly of the same real Essence, should have different Properties, as that two Figures partaking in the same real Essence of a Circle, should have different Properties", 418. 
Si un individuo corresponde a la idea nominal que el entendimiento se ha formado de una especie particular-idea que implica, igualmente, las condiciones de la identidad trans-temporal y de sus propiedades específicas-, dicho individuo pertenece, para aquel que cree en las especies individuales, a dicha especie al diferenciarse por completo de otros individuos de otras especies. Locke relativiza esta realidad por el hecho de que la especie no es sino nominal y sometida a revisión. Subraya que para "pensar y juzgar correctamente" la identidad, "es necesario considerar la idea que representa la palabra a la que se aplica [...] tal es, en efecto, la idea que pertenece a dicho nombre, tal debe ser la identidad correspondiente". 34

Nuestro autor precisa que cuando "buscamos aquello que hace el mismo Espíritu, el mismo hombre o la misma persona, nos hace falta fijar en nuestro espíritu las ideas de Espíritu, de hombre y de persona, $\mathrm{y}$, habiendo decidido en nosotros mismos lo que entendemos por aquello, no nos resultará difícil determinar, en estos tres casos, otros parecidos, cuando hay identidad". 35

Desde este momento, se trata de definir por nosotros mismos el contenido de la idea de identidad en general y, más específicamente, de la idea de identidad personal.

Una primera aproximación consiste en proponer una definición muy larga de identidad, la cual se aplicaría a toda cosa. Para hacer esto, Locke introduce el criterio de la existencia, que se caracteriza por las determinaciones de temporalidad (T) y de espacio (E) singulares. Nuestro filósofo sostiene que dos cosas de la misma especie no pueden existir en el mismo momento (T1) en un espacio idéntico (E1), o, en otros términos, que la existencia de una determinada cosa en T1 y E1 excluye la existencia de toda otra cosa de la misma especie en T1 y E1. Una misma cosa ya no puede existir simultáneamente en T1 y T2 o en E1 y E2. La identi-

${ }^{34}$ John Locke, "Identité et différence", § 7, 143: "but to conceive, and judge of it [identity] aright, we must consider what idea the word it is applied to stands for. [...] for such as is the idea belonging to that name, such must be the identity", 142.

${ }^{35} \mathrm{Idem}, \S 15,163$ : "But yet when we will enquire, what makes the same spirit, man, or person, we must fix the ideas of spirit, man, or person, in our minds; and having resolved with our selves what we mean by them, it will not be hard to determine, in either of them, or the like, when it is the same, and when not", 162. 
BERNARD SCHUMACHER

dad de una cosa no está constituida simplemente por su existencia ontológica particular, sino más específicamente por su existencia "en tal momento y en tal lugar". ${ }^{36}$ Está conformada por las determinaciones espacio-temporales; dicho de otra forma, por criterios externos a la 'naturaleza' de la cosa.

Cuando veamos nosotros, escribe Locke, que alguna cosa está en algún lugar, en algún momento del tiempo, podemos estar seguros que ciertamente es esa cosa (sea cual sea, por otra parte, su naturaleza), y no alguna otra, que en el mismo momento exista en otro lugar, con lo parecidas e indiscernibles que, por lo demás, pudieran ser. ${ }^{37}$

La determinación espacio-temporal inherente a toda existencia terrestre parece, sin embargo, insuficiente para determinar la identidad. Hace falta añadir el criterio de origen. En efecto, una cosa particular no puede tener dos comienzos de su existencia, como dos cosas no pueden tener uno solo.

Aquello que tuvo un solo comienzo es, pues, la misma cosa, y lo que ha comenzado a existir en lugares y momentos diferentes no es la misma cosa, sino una diferente. ${ }^{38}$

Si bien la identidad de una cosa pertenece a una misma especie, se define también tanto por sus características espacio-temporales como por el comienzo de su existencia, excluyendo así todas las otras cosas de la misma especie; no obstante, puede coexistir simultáneamente en

${ }^{36}$ Idem, $\S 1,135$ : "such a time in such a place", 134.

${ }^{37}$ Idem, $\S 1,133$ : "When we see any thing to be in any place in any instant of time, we are sure, (be it what it will) that it is that very thing, and not another, which at that same time exists in another place, how like and undistinguishable soever it may be in all other respects", 132.

${ }^{38}$ Idem, $\S 1$, 135: "That therefore that had one beginning is the same thing, and that which had a different beginning in time and place from that, is not the same but divers", 134]. Una discusión similar se encuentra en la reciente discusión de la asimetría de nuestras actitudes en lo que concierne a la muerte y al nacimiento/concepción en el ámbito del desafío de la 'nada de la muerte' de Epicuro y de Lucrecio. Thomas Nagel, por ejemplo, conibe el nacimiento/concepción -referencia hecha a un momento particular de la temporalidad y a un espacio dado- como una propiedad constitutiva de la identidad personal de ' $\mathrm{x}$ '. Ver Bernard N. Schumacher, Confrontations avec la mort. La philosophie contemporaine et la question de la mort, 262ss. 
T1 y E1 con una cosa de otra especie. ${ }^{39}$ Nuestro filósofo distingue las especies - a la cual se atribuye una identidad específica- en tres categorías de substancia: divina, espiritual finita y corporal. Mientras que la substancia divina es siempre idéntica a sí misma, siendo eterna y omnipresente, la identidad de la substancia de la inteligencia finita, como la del alma humana, tiene por origen su desgarramiento fuera de la nada y su proyección en la espacio-temporalidad. De la misma manera para la substancia corporal, que es idéntica a sí misma en la medida en que ninguna materia le es añadida o sustraida de modo fundamental. Sin embargo, es lógicamente posible que dos substancias distintas puedan coexistir simultáneamente en $\mathrm{T} 1$ y E1:40 se piensa en una substancia espiritual como el alma humana coexistiendo con una substancia corporal, el cuerpo humano, como lo supone el dualismo cartesiano. Una existencia tal, concomitante, es al contrario, imposible para dos cosas que tienen la misma substancia. En efecto, no sería posible distinguirlas una de la otra, dado que no formarían sino una sola cosa.

La identidad de una cosa se sitúa también en el plano del presente más que en el nivel de la continuidad temporal, a pesar de los cambios accidentales. Locke distingue, en el orden de las substancias corporales, dos subgrupos: la masa y lo viviente. Dos criterios distintos de identidad los definen. Por una parte, la identidad de la simple masa corporal -que es un "agregado de corpúsculos materiales"-, ${ }^{41}$ depende de la masa idéntica de los átomos que la constituyen, es decir, que hay cambio de identidad cuando desaparece o se añade un átomo. Por otra parte, la identidad del cuerpo viviente no reside en la estabilidad de la masa de átomos, sino en la disposición particular de los átomos

${ }^{39} \mathrm{Idem}, \S 1$ et 3,135 et 137 : "que es imposible que dos cosas de la misma especie sean o existan en el mismo instante en el mismo lugars [...] es la existencia misma la que para todas las clases de seres asigna a cada uno un tiempo y un espacio determinados, que no pueden ser comunes a dos seres de la misma especie." ["It being impossible for two thing of the same kind, to be or exist in the same instant, in the very same place [...] is existence itself, which determines a being of any sort to a particular time and place incommunicable to two beings of the same kind", 134 et 136].

${ }^{40} I d e m, \S 2,135$ : "Estas tres clases de substancias [...] no se excluyen la una de la otra de la ocupación de un mismo lugar" ["these three sorts of substances [...] do not exclude one another out of the same place", 134].

${ }^{41}$ Idem, § 4, 139: "the cohesion of particles of matter", 138. 
BERNARD SCHUMACHER

que forman las diferentes partes de un cuerpo viviente. Éstas comparten "una sola vida común" 42 y trabajan con miras al completo desarrollo de lo viviente y de la conservación de su existencia. Encontramos aquí, aunque Locke no haga mención explícita, la idea aristotélica de que lo viviente está constituido por un principio intrínseco, una fuerza 'inteligente' organizadora y creadora, que ordena lo viviente con constante regularidad hacia un fin preciso determinado, que es el desarrollo último de su 'naturaleza'. El célebre fisiólogo y padre del método experimental en medicina, Claude Bernard, infiere la existencia de un principio de orientación, hacia un fin e 'inteligente', inscrito en la naturaleza de lo viviente, que orienta el despliegue de sus diversas formas y funciones, a partir del comienzo de su existencia y hasta la actualización de su ser. El acontecimiento biológico aparece como una serie de actos o de fenómenos agrupados, concertados, armonizados de tal manera que se llegue a un resultado determinado. La vida biológica no es reductible meramente a sus procesos químicos y físicos, sino que existe una idea directriz, un plan vital, una vis formativa anclada en lo más íntimo de lo viviente, constituyendo su centro por el cual se encamina hacia un telos. Pero, al no ser accesible más que para la inteligencia, este eidos escapa al conocimiento sensible.

En todo germen vivo - precisa Claude Bernard-, hay una idea creadora que se desarrolla y manifiesta por la organización. Durante toda su duración, lo viviente queda bajo la influencia de esta misma fuerza vital creadora, y la muerte llega cuando aquélla ya no puede realizarse. Aquí, como en todos lados, deriva todo de la idea, quien, solamente ella, crea y dirige. ${ }^{43}$

De manera análoga, la planta comparte, a los ojos de Locke, una sola y misma vida espresada por una misma organización que la conserva en la existencia; permanece idéntica a sí misma a pesar de que se añada o retire cierto número de átomos. El mismo discurso se aplica

${ }^{42}$ Ibidem: "as it partakes of the same life", 138.

${ }^{43}$ Claude Bernard, Introduction à l'étude de la médecine expérimentale, 1920, Paris, Delagrave, 147-8. 
al animal. ${ }^{44}$ Puede preguntarse, justamente, si lo mismo se aplicaría al ser humano, que se caracteriza igualmente por una corporeidad biológica. ¿Su identidad corresponde a lo que describe el dualismo cartesiano, el monismo de la unidad substancial aristotélica o la substancia del alma platónica? Tomando su distancia de dichas tradiciones antropológicas, el filósofo inglés concibe la identidad humana de la misma manera que aquella de la planta y del animal; en otras palabras, como la conservación de la existencia temporal de un cuerpo organizado. La identidad humana está, desde entonces, constituida por "la participación de la misma vida ininterrumpida, por el flujo constante de partículas de materia, en sucesión vitalmente unida al mismo cuerpo organizado. ${ }^{45}$

Un poco más adelante, Locke precisa que esta identidad -como, por lo demás, la del animal- no reside en cosa alguna:

Salvo en un cuerpo organizado, apto para desempeñar su función en un momento dado, y enseguida, mantenerse con vida bajo una sola organización por medio de un flujo de corpúsculos materiales que se unen a él y se sustituyen los unos a los otros. ${ }^{46}$

Sin embargo, una definición como la anterior resulta problemática. En efecto, si la planta, el animal y el ser humano tienen el mismo criterio de identidad: ¿cómo se les podría diferenciar? ¿No debería más bien atribuírseles un solo nombre? Locke no admite tal consecuencia, sosteniendo que se distinguen en el plano de la forma y de la estructura particular de su organismo y, se podría precisar, de su complejidad. Así, el ser humano se caracteriza por una forma específica,

44 “"El mismo animal [...] es la misma vida continuada, comunicada a diferentes corpúsculos de materia, que se encuentran unidos uno después de otro a dicho cuerpo vivo organizado", John Locke, "Identité et différence", § 8, 145 ["the same animal [...] is the same continued life communicated to different particles of matter, as they happen successively to be united to that organized living body," 144].

${ }^{45}$ Idem, $\S 6,141$ : "a participation of the same continued life, by constantly fleeting particles of matter, in succession vitally united to the same organized body", 140.

${ }^{46} \mathrm{Idem}, \S 6$, 143: "one fitly organized body taken in any one instant, and from thence continued under one organization of life in several successively fleeting particles of matter, united to it", 142. 
BERNARD SCHUMACHER

a saber, que es un "animal de una forma determinada". ${ }^{47}$ No obstante, nos habíamos ocupado ya de un mismo ser humano, tal que su forma y su estructura fundamental de tipo corporal son idénticas a través del tiempo.

La idea de un hombre consiste solamente -afirma el filósofo inglés al final de su capítulo- en la unidad de lo viviente de ciertas partes según una cierta forma, y mientras por largo tiempo dicha unidad y dicha forma de lo viviente permanezcan dentro de un mismo conjunto, idéntico a sí mismo a través del cambio y del flujo continuo de corpúsculos que lo componen, entonces será el mismo hombre. ${ }^{48}$

Locke define así al ser humano, desde un punto de vista estrictamente biológico, excluyendo, por lo mismo, la racionalidad del núcleo de su definición. Es interesante notar que esta concepción de la identidad humana entraña un cierto número de consecuencias implícitas que el filósofo inglés no desarrolla. Un ser humano que estuviera, por ejemplo, profundamente discapacitado en el plano mental, es decir, que no tuviera, para retomar una expresión de Locke "más racionalidad que un gato o un periquito", ${ }^{49}$ sería un ser humano. Todo viviente que completara los criterios de la identidad humana siempre sería considerado como ser humano, independientemente del ejercicio de las facultades de la razón y de la voluntad, de la auto-conciencia y de la conciencia moral. El hecho de dormir profundamente o de estar ebrio - dos ejemplos mencionados por Locke, que ilustran la privación momentánea del ejercicio de la conciencia en los dos sentidos antes señalados- no altera en nada la identidad humana a través del tiempo. Del mismo modo, no se identifica a un animal, que estuviera dotado de razón, de comprensión semántica de las palabras -el filósofo hace referencia a la historia verosímil de un periquito en Brasil_ ${ }^{50}$, con un ser

${ }^{47}$ Idem, $\S 8$, 145: “an animal of such a certain form”, 144.

${ }^{48} \mathrm{Idem}, \S 29$, 181: "the idea of a man be, but the vital union of parts in a certain shape; as long as that vital union and shape remains, in a concrete no otherwise the same, but by a continued succession of fleeting particles, it will be the same man", 180 .

${ }^{49} \mathrm{Idem}, \S 8,145$ : "though it had no more reason all its life, than a cat or a parrot", 144.

${ }^{50}$ Ver idem, $\S 8,145-7$ [144-6]. Si bien la historia del periquito que habla pudiera resultar verdadera, y que esta palabra debiera manifestar con certeza la presencia de una inteligencia y 
humano. La identidad de este último se sitúa únicamente en el plano biológico, excluyendo, por lo mismo, el ejercicio de la racionalidad, de la auto-conciencia o de la conciencia moral, así como una substancia espiritual tal como el alma humana. La posición lockeana permite mantener -como lo afirman buen número de filósofos bioéticos- una misma identidad entre un embrión humano desde su concepción y un ser humano al final de su vida, o entre un ser humano loco o senil y un ser humano racional y lleno de sentido común. Una continuidad identataria tal, que va desde la concepción justo hasta el momento del deceso, no puede ser mantenida salvo en referencia a la dimensión biológica. Si se renuncia a fundar la identidad humana sobre esta dimensión y se elige fundarla más bien sobre una substancia pensante como el alma humana -y en la medida en que el alma humana fuera incorruptible- sería posible concebir una identidad humana que trascendiera a la muerte en otros cuerpos, humanos o animales.

A los ojos de Locke, definir al ser humano según otros criterios que no fueran el biológico, sería hacer "un uso muy extraño" 51 del término ser humano. Puede cuestionarse qué razón pudo tener el filósofo inglés para emitar tal juicio. Curiosamente, no proporciona ningún argumento racional, pero se refiere al sentido común que no considera, por ejemplo, que un cerdo que hubiera sido investido por el alma de mi hijo Nicolás sería, por tanto, un ser humano. Remitir al sentido común para sostener la verdad de una afirmación sobre la realidad de las cosas no constituye, sin embargo, una prueba desde un punto de vista argumentativo. Locke no hace sino afirmar una verdad a priori. Por otra parte, veremos que no siempre atribuye al sentido común el mismo valor que aquí, porque en otro lado rechaza la intuición del sentido común, según la cual el cuerpo humano es parte constitutiva de la persona. ${ }^{52}$ Entonces, su argumento podría volverse contra él mismo y, al apoyarse sobre el

de una conciencia, entonces deberíamos considerarlo como una persona. Locke no franqueó este paso, dejando prudentemente a los naturalistas el cuidado de profundizar la cuestión. Tres siglos más tarde, Singer defiende dicha posibilidad al conceder el estatus de persona a ciertos animales conscientes de sí mismos.

${ }^{51}$ Idem, § 6, 143: “a very strange use", 142.

${ }^{52}$ Ver idem, § 15, 163 [162]. 
BERNARD SCHUMACHER

sentido común, reprocharle por hacer "un uso muy extraño" del término persona cuando concibe una persona sin cuerpo.

Antes de presentar su definición de persona, el filósofo inglés introduce, de manera sutil, un elemento clave de su discusión sobre el ser humano: el rechazo categórico para identificar los términos 'ser humano' y 'persona'. Esta distinción está confirmada más expresamente en las primeras líneas del parágrafo siguiente, en el que Locke trata sobre la identidad humana. Afirma, sin tapujos, que no necesariamente todos los seres humanos son personas. Dicha tesis fundamental se opone a la "manera normal de hablar" descrita en el parágrafo 15, según la cual "'la misma persona' y 'el mismo hombre' representan una sola y misma cosa". ${ }^{53}$ Así, podemos leer en el parágrafo 7:

Una cosa es ser la misma substancia; otra, ser el mismo hombre; y una tercera, ser la misma persona, si "persona", "hombre" y "substancia" son tres nombres que representan tres ideas diferentes; tal es, en efecto, la idea que pertenece a este nombre, tal debe ser la identidad correspondiente. $^{54}$

Por idea de persona, Locke entiende aquí la esencia nominal de la persona. Ésta se distingue, a la vez, de la substancia-en este contexto, un alma pensante- $\mathrm{y}$ del ser humano definido únicamente por su corporeidad -que no le es en adelante de ninguna utilidad para resolver el problema fundamental que le ocupa, a saber, el juicio de los actos morales personales libres. Puesto que de inicio excluyó de su reflexión la identidad del ser humano, le hace falta definir la identidad de la persona humana.

${ }^{53} \mathrm{Idem}, \S 15$, 163: "that in the ordinary way of speaking, the same person, and the same man, stand for one and the same thing", 162.

${ }^{54} \mathrm{Idem}, \S 7,143$ : "It being one thing to be the same substance, another the same man, and a third the same person, if person, man, and substance, are three names standing for different ideas; for such as is the idea belonging to that name, such must be the identity", 142 . 


\section{La persona humana como auto-conciencia performante}

En las primeras líneas del célebre parágrafo 9 de su capítulo 27, Locke define a la persona humana como:

Un ser pensante e inteligente, dotado de razón y de reflexión, y que puede considerarse a sí mismo como sí mismo, una misma cosa pensante en diferentes tiempos y lugares. ${ }^{55}$

Tomada tal cual por un número creciente de filósofos bioéticos contemporáneos, esta definición contiene dos partes distintas. Por una, hace referencia explícitamente a uno de los elementos de la definición tradicional de persona desarrollada por Boecio en el siglo V: la racionalidad. Ésta se encuentra expresada en la definición de Locke con la ayuda de cuatro términos, en los cuales el sentido de ninguna manera es preciso, dado que pueden revestir distintos significados: el pensamiento, la inteligencia, la razón y, en fin, la reflexión. El pasaje citado enfatiza igualmente la auto-conciencia ejercida, la cual "es lo que hace que cada uno sea lo que se denomina sí mismo y que se distingue de todas las otras cosas pensantes. ${ }^{56}$ La unidad identataria de la persona en T1 y E1 no se funda - como lo afirma la tradición seguida desde Boecio hasta Descartes- sobre una substancia particular, que sea corpórea y/o incorpórea. No es mediante un simple acto de pensar "que cada uno sea lo que se denomina sí mismo", ${ }^{57}$ sino por la operación performante de la conciencia, que recoge las actividades de la razón -juicio moral incluido- a la unidad del yo. Una persona no puede afirmar que un pensamiento o una acción es suya salvo en la medida en que se la apropie mediante la auto-conciencia. "La misma conciencia que tiene de sus pensamientos y acciones presentes, que ahora es sí mismo por sí

${ }^{55}$ John Locke, "Identité et différence", § 9, 149: "a thinking intelligent being, that has reason and reflection, and can consider it self as it self, the same thinking thing in different times and places", 148.

${ }^{56} \mathrm{Idem}, \S 9,151$ : "an it is that, that makes every one to be, what he calls self; and thereby distinguishes himself from all other thinking things", 150.

${ }^{57}$ Idem, $\S 9,151$ : "it [consciousness] is that, that makes every one to be, what he calls self', 150. 
BERNARD SCHUMACHER

mismo". ${ }^{58}$ A falta de una atribución tal, el pensamiento o la acción particular pertenecerían a algún otro yo.

No obstante, la cuestión esencial, a los ojos de Locke, no es la de definir la identidad de una persona en un momento dado y en un lugar preciso, sino a través del tiempo y en lugares distintos, como lo sugiere la última parte de la definición precedentemente citada. ¿Sobre qué se funda esta identidad personal a través del tiempo y los lugares? Consiste en el ejercicio performante de la conciencia, que se la reapropia y se la imputa con la ayuda de la memoria, los pensamientos y las acciones morales pasadas en el seno de un mismo yo, que por ello mismo se distingue de las demás personas. No es la memoria como tal la que consituye la identidad personal a través del tiempo, pero definitivamente reviste una importancia capital. La memoria es útil no en cuanto hace emerger de la sombra una idea o una acción pasada, sino, más específicamente, en cuanto permite que un pensamiento o una acción que había sido percibida intencionalmente por una conciencia en T1 vuelva a ser una percepción intencional actual en T2 en el seno de la conciencia. Una idea o acción pasada que no sea apropiada e imputada por la conciencia en T2 no pertenecería a la identidad de la persona, pues le resultaría fundamentalmente extranjera. ${ }^{59}$

La identidad de tal persona se extiende - destaca Locke- tan lejos como dicha conciencia pueda atender retrospectivamente toda acción o pensamiento pasado; es el mismo yo ahora que en el pasado, y el yo que ha ejecutado esa acción es el mismo que aquel que, en el presente, reflexiona sobre ella. ${ }^{60}$

${ }^{58} \mathrm{Idem}, \S 10,153$ : "the same consciousness it has of its present thoughts and actions, that it is self to it self now", 152. "Por mi pensamiento sobre mí, mi acción sobre mí, al apropiármelo por la conciencia", Locke, Idem, $\S 24,175$ : "by my consciousness make my own thought and action", 174.

${ }^{59}$ John Locke anota que se trata de una "representación presente de un acto pasado", "Identité et différence", $\S 13,155$ : "a present representation of a past action", 154. "La identidad personal no se extiende más lejos de lo que llega la conciencia", § 14, 159 ["that personal identity reaching no farther than consciousness reaches", 158].

${ }^{60} \mathrm{Idem}, \S 9$, 151: "the sameness of a rational being: and as far as this consciousness can be extended backwards to any past action or thought, so far reaches the identity of that person; it is the same self now it was then; and it is by the same self with this present one that reflects on it, that that action was done", 150. 
Aquí la conjunción 'o' significa que no es necesario que la conciencia, por intermedio de la memoria, se apropie tanto de pensamientos como de acciones pasados, incluso si el filósofo inglés se contradice algunas líneas más adelante, al afirmar tal necesidad o incluso al referirse únicamente a las acciones. ${ }^{61}$ Nuestro autor afirma claramente que no se puede hablar de una misma persona a través del tiempo, a menos que se esté en presencia de una conciencia performante, a saber, que ejerce la apropiación y la imputación de las cuales hemos hablado más arriba. La misma performance es exigida cuando se quiere designar tal ser humano como persona, con la diferencia de que la imputación del pensamiento o de la acción se sitúa en el presente.

Esta definición lockeana trans-temporal de la persona comporta una primera dificultad: ninguna conciencia humana se halla en condiciones de englobar, de una sola vez, todos sus pensamientos o acciones pasadas. La razón de tal imposibilidad reside en la debilidad esencial de la memoria, debida a la contingencia ontológica de la persona. La conciencia humana, incluida aquella que esté dotada de una memoria extremadamente performante, se caracteriza por el olvido. Sería imposible ser una misma persona a través del tiempo si para ello hiciera falta disponer de una memoria absoluta. Un medio de resolver esta dificultad consistiría en exigir que la conciencia se imputara al menos un pensamiento o acción pasada. Locke afirma que, para ser considerado como una persona que mantiene su identidad a través del tiempo, un individuo debe ser capaz de:

Repetir la idea de una acción pasada con la misma conciencia que haya tenido la primera vez, y la misma conciencia que aquella que tenga de la acción presente, en esta misma medida será el mismo yo personal. Puesto que es por la conciencia que tiene pensamientos y acciones presentes, que ahora él es sí para sí mismo, y que así le quedará el mismo sí en la medida exacta en que la conciencia se extenderá a las acciones pasadas o por venir. ${ }^{62}$

${ }^{61}$ Ver idem, § 10, 153 [152], § 16, 163 [162].

${ }^{62} \mathrm{Idem}, \S 10,153$ : "For as far any intelligent being can repeat the idea of any past action with the same consciousness it has of its present thoughts and actions, that it is self to it self now, and so will be the same self as far as the same consciousness can extend to actions past or to come”, 152 . 
BERNARD SCHUMACHER

Al basar su definición de persona en la apropiación e imputación de pensamientos o acciones morales presentes y pasadas por la conciencia inmediata, que deviene en adelante el principio unificador en un 'yo' de sus mismas acciones y pensamientos, Locke rompe brutalmente con la tradición. Esta ruptura revolucionaria consiste en desubstancializar la persona y en determinarla por el ejercicio del dominio del sujeto sobre sí mismo. "Así que el yo no está determinado por la identidad o diversidad de la substancia, de la cual no puede estar seguro, sino sólo por la identidad de la conciencia". ${ }^{63}$ Precisa el filósofo inglés:

Resulta manifiesto que la simple conciencia, tan lejos como pueda llegar, inclusive si es hasta épocas históricas pasadas, reúne las existencias y las acciones alejadas en el tiempo en el seno de la misma persona, de la misma forma que lo hace para la existencia y las acciones del momento inmediatamente precedente. De suerte que todo lo que tiene la conciencia de acciones presentes y pasadas es la misma persona a la cual ellas pertenecen conjuntamente. ${ }^{64}$

Un poco más adelante, añade:

La misma substancia numérica no está considerada para hacer el mismo yo: pero la continuación de la misma conciencia, en la cual muchas substancias pueden haber sido reunidas, y de nuevo separadas de ella, solamente en la medida en que ellas han mantenido una unión viva con aquello en lo que la conciencia reside, forman parte del mismo yo. ${ }^{65}$

${ }^{63} \mathrm{Idem}, \S 23,173$ : "So that self is not determined by identity or diversity of substance, which it cannot be sure of, but only by identity of consciousness", 172 .

${ }^{64} \mathrm{Idem}, \S 16$, 163: "it is plain consciousness, as far as ever it can be extended, should it be to the ages past, unites existences, and actions, very remote in time, into the same person, as well as it does the existence and actions of the immediately preceding moment: so that whatever has the consciousness of present and past actions, is the same person to whom they both belong," 162.

${ }^{65}$ Idem, $\S 25,175$ : "the same numerical substance is not considered, as making the same self : but the same continued consciousness, in which several substances may have been united, and again separated from it, which, whilst they continued in a vital union with that, wherein this consciousness then resided, made a part of that same self', 174. 
Sólo la identidad de la conciencia está en posibilidad de unir existencias alejadas en el seno de la misma persona. La identidad de la substancia es incapaz.

Puesto que, sea lo que fuere la substancia y su consititución, sin la conciencia no hay persona: y un cadáver podría ser una persona, tanto como cualquier clase de substancia podría serlo sin conciencia. ${ }^{66}$

Recordemos que, para Locke, la definición de persona es, ante todo, un "término jurídico". ${ }^{67} \mathrm{Al}$ referirse al veredicto del juicio que constituye el punto de partida de su reflexión, sostiene que:

El veredicto deberá ser justificado por la conciencia que todas las personas han de tener, en tanto que ellas mismas son las mismas que, precisamente, han cometido dichos actos y merecen ser castigados por ellos, sea cual sea el cuerpo [las substancias corporales] en el cual se muestren o las substancias [las espirituales] a las que esta conciencia esté ligada. ${ }^{68}$

Si bien a primera vista puede parecer que el filósofo inglés excluye de su definición de persona toda substancia corporal o espiritual, no es menos cierto que exige la presencia de una substancia. Es necesario, de esta forma, distinguir dos niveles de comprehensión cuando se habla de substancia. Por una parte, se puede concebir la substancia corporal y/o pensante como siendo un accidente de la persona, es decir, que no existe necesidad alguna, para ser una persona, de estar encarnado dentro de tal substancia corporal o dentro de tal substancia pensante particu-

${ }^{66} \mathrm{Idem}, \S 23,171$ : "Nothing but consciousness can unite remote existences into the same person, the identity of substance will not do it. For whatever substance there is, however framed, without consciousness, there is no person: and a carcase may be a person, as well as any sort of substance be so without consciousness", 170 .

${ }^{67}$ Idem, § 26, 177: “a forensic term”, 176.

${ }^{68}$ Idem, § 26, 179: "The sentence shall be justified by the consciousness all person shall have, that they themselves in what bodies soever they appear, or what substances soever that consciousness adheres to, are the same, that committed those actions, and deserve that punishment for them", 178. 
BERNARD SCHUMACHER

lares. Por la otra, se puede ver la substancia corporal y/o pensante como un elemento indispensable para la definición de la persona, pero no constitutivo de dicha definción: la auto-conciencia performante está, de este modo, necesariamente encarnada durante su existencia temporal dentro de una substancia corporal que forma "una parte de sí mismo [del sujeto]", ${ }^{69}$ pero que no es, en absoluto, constitutiva de dicha auto-conciencia. Ciertamente, precisa Locke, el yo mantiene una "relación de simpatía" con su cuerpo "por el cual se preocupa", 70 pero este cuerpo particular en el cual se encuentra no es constitutivo de su ser personal. Otro cuerpo humano bien podría realizar la tarea. Para existir en el mundo y en la historia, la auto-conciencia performante tiene necesidad de una substancia corporal humana en general, y no de tal o cual substancia corporal en particular. La individualidad personal es fundamentalmente independiente de toda substancia corporal específica. Esta afirmación vale de igual manera para el estado post mortem, en el que la persona puede estar ligada a una substancia pensante general y no individualizante, o eventualmente, a una substancia corporal general en el caso de la resurrección (en la cual Locke cree).

Hacer abstracción de la substancia de la persona, por considerarla ante todo como una entidad performante, entraña un cierto número de consecuencias. Por ejemplo, una persona puede encontrarse en tiempos o lugares distintos en varias substancias corporales y/o pensantes, o, al contrario, una substancia corporal y/o pensante puede servir de soporte a varias personas. La substitución de una substancia particular por otra no altera en nada la identidad de la persona. Locke no podría ser más claro que cuando anota:

La identidad personal no depende de ninguna otra cosa [salvo de la presencia de la misma conciencia], la cual estaría anexada sólo a una substancia individual, o podría ser continuada en una sucesión de numerosas substancias [...] La misma conciencia reúne las acciones alejadas

${ }^{69}$ Idem, § 10, 153: "a part of himself”, 152.

${ }^{70} \mathrm{Idem}, \S 11,153$ : "he sympathizes and is concerned for them [the limbs of his body]", 152. 
en el seno de la misma persona, sean cuales fueren las substancias que hubieran contribuido a su producción. ${ }^{71}$

En varias ocasiones, el filósofo inglés anota que "substancias diferentes pueden estar unidas en una sola persona por la misma conciencia". ${ }^{72}$ Para ilustrar su propósito, menciona el caso de un conocido -que pasaba, precisa nuestro autor, por un gran espíritu a los ojos de sus contemporáneos y autor de publicaciones eruditas- que estaba convencido de que su alma era la de Sócrates. ¿Estamos realmente en presencia del gran filósofo griego, podría preguntarse, cuando la substancia corporal particular considerada como a resguardo es distinta? Locke responde de manera negativa. Sin embargo, no justifica dicha respuesta por la diferencia de substancias corporales, sino por el hecho de que esta persona no tenía la conciencia de los pensamientos ni de las acciones del maestro de Platón. ¿Qué es necesario concluir? Si la conciencia de una persona en T1 -por ejemplo, Nicolás-no está en condiciones de apropiarse y de imputarse una acción o pensamiento de Sócrates en Atenas, o de Néstor, respectivamente, de Tersites en el sitio de Troya -ejemplos propuestos por Locke-, es que nos hemos ocupado de dos personas distintas. ${ }^{73}$ Sucedería lo mismo en el caso de la substancia pensante, que estaría ligada a la substancia corporal de Sócrates, de Néstor o de Tersites, y sería idéntica a la de Nicolás. Para afirmar que existe una identidad de persona entre Sócrates, Néstor o Tersites y Nicolás, hace falta que este último se apropie y se impute al menos un pensamiento o una acción de Sócrates, Néstor o Tersites. El filósofo inglés precisa que "bastaría que él tuviera una sola vez conciencia de una acción de

${ }^{71} I d e m, \S 10,153$ : "personal identity depends on that only [the same consciousness], whether it be annexed only to one individual substance, or can be continued in a succession of several substances. [...] whether it (i.e. consciousness) be annexed only to one individual substance, or can be continued in a succession of several substances", 152. "Ya que resulta evidente que la identidad personal estaría siempre determinada por la conciencia, fuera o no que dicha conciencia estuviese anexada a alguna substancia inmaterial individual." $\S 23,173$ ["since it is evident the personal identity would equally be determined by the consciousness, whether that consciousness were annexed to some individual immaterial substance or no", 172].

${ }^{72}$ Idem, $\S 10,151-3$ : "Different substances, by the same consciousness (where they do partake in it) being united into one person", 150-2.

${ }^{73}$ Ver John Locke, idem, § 14, 159-61 [158-60]. 
BERNARD SCHUMACHER

Néstor, cualquiera que ésta fuera, para que se encontrara con que no es sino una persona con Néstor. ${ }^{74}$

Un razonamiento similar se aplica en el caso de la persona que sufriera un episodio de amnesia, pero permaneciendo consciente de sí misma: se asistiría a la emergencia de una nueva persona después de la crisis de amnesia; aunque compartiendo la misma substancia corporal, serían dos personas distintas. Se seguiría que la segunda persona (T2) no sería en absoluto responsable de los actos morales de la primera persona (T1), debido a que se encontraría en la imposibilidad de apropiarse y de imputarse los pensamientos o las acciones pasadas en T1. La misma afirmación vale para la persona alerta o sobria en T2, que no se puede imputar una acción moral al velar durante el sueño o en estado de ebriedad en T1. ${ }^{75} \mathrm{La}$ antropología lockeana debe, necesariamente, afirmar que nos habríamos ocupado de personas distintas en una substancia corporal idéntica.

Supongamos ahora que Nicolás no solamente está convencido de que su alma es la de Sócrates, sino también, y sobre todo, que él se apropia e imputa con toda autenticidad subjetiva un pensamiento o una acción de Sócrates. Según la tesis de Locke, deberíamos entonces convenir en que la persona de Nicolás y la de Sócrates son en realidad una sola y misma persona. No nos sería permitido ponerlo en duda. Se encuentra tal certeza de parte del filósofo inglés en una experiencia de pensamiento, que propone al lector:

Si tuviera conciencia de haber visto el Arca y el diluvio, como Noé, como tengo conciencia de haber visto la crecida del Támesis el invierno anterior, o como tengo ahora conciencia de escribir, no podría dudar que yo escribo esto ahora, que yo vi la crecida del Támesis el invierno anterior, y que habría visto la tierra inundada por el Diluvio, yo sería el mismo yo, en cualquier substancia que os agrade, que no puedo dudar de que yo que escribo soy el mismo yo o mí mismo que era ayer, mientras que en el presente yo escribo (que yo estoy enteramente constituido o no por la

${ }^{74}$ Idem, $\S 14,161$, traducción ligeramnte modificada: "But let him once find himself conscious of any of the actions of Nestor, he then finds himself the same person with Nestor", 160].

${ }^{75}$ Ver John Locke, idem, § 19, 167 [166]. 
misma substancia, material o inmaterial). Pues, en cuanto al punto de ser el mismo yo, importa poco que este yo de hoy esté hecho de la misma substancia o de otras. Puesto que también soy justamente cuidadoso y responsable de un acto realizado hace mil años, apropiado por mí ahora, por esta auto-conciencia, como lo soy por lo que he hecho hace un instante. ${ }^{76}$

La certeza sobre la que se apoya Nicolás para afirmar que no es sino uno junto con Sócrates en el plano de su persona -independientemente de la substancia corporal y de la substancia pensante en las cuales se encuentra- se funda únicamente por y en su propia subjetividad. Lo anterior hace recordar la célebre experiencia del pensamiento donde la substancia pensante de un príncipe, con la conciencia de su vida pasada, se transporta al cuerpo de un zapatero remendón, de quien la substancia pensante al poco tiempo habría desaparecido. ${ }^{77}$ Nicolás es la única persona capaz de afirmar con certeza absoluta-en el plano de su subjetividad-que él es idéntico a Sócrates o a Noé, y ello en la medida en que su conciencia se haya apropiado e imputado un

${ }^{76}$ Idem, $\S 16,163$ : "Had I the same consciousness, that I saw the Ark and Noah's flood, as I saw an overflowing of Thames last winter, or as that I write now, I could no more doubt that I write this now, that saw the Thames overflowed last winter, and the viewed the flood at the general Deluge, was the same self, place that self in what Substance you please, than that I write this am the same my self now whilst I write (whether I consist of all the same substance, material or immaterial, or no) that I was yesterday. For as to this point of being the same self, it matters not whether this present self be made up of the same or other substances, I being as much concerned, and as justly accountable for any action was done thousand years since, appropriated to me now by this self-consciousness, as I am, for what I did the last moment", 162.

${ }^{77}$ Puede preguntarse si el príncipe en el cuerpo del remendón es idéntico sea al príncipe en el cuerpo del príncipe, sea en el del remendón, o si estamos en presencia de una nueva persona. Se puede deducir, en un primer momento, que se trata del mismo ser humano, pues la substancia corporal del remendón permanece sin cambiar antes y después de la transferencia. Se puede sostener, en un segundo momento, que nos hemos ocupado de la persona del príncipe en la substancia corporal del zapatero en la medida en que el príncipe se apropia e imputa un pensamiento o acción pasada realizada en la substancia corporal del príncipe. Ver John Locke, "Identité et différence", $\S 15,161$ [160]: "For should the soul of a prince, carrying with it the consciousness of the prince's past life, enter and inform the body of a cobler, as soon as deserted by his own soul, every one sees, he would be the same person with the prince, accountable only for the prince's actions: but who would say it was the same man? The body too goes to the making the man, and would, I guess, to every body determine the man in this case, wherein the soul, with all its princely thoughts about it, would not make another man: but he would be the same cobbler to every one besides himself." 
BERNARD SCHUMACHER

pensamiento o acción del filósofo griego o del patriarca bíblico. Locke afirma sin ambigüedad que "si Sócrates y el actual alcalde de Quinborough se pusieran de acuerdo, serían la misma persona". ${ }^{78}$ Se puede llegar a deducir que la identidad de la persona es muestra de la certeza que se tiene consigo mismo; en otras palabras, que la identidad se funda en última instancia en la subjetividad de la persona. Todo criterio de identificación externo a la subjetividad como, por ejemplo, la substancia corporal o la substancia pensante, está excluido. Seguramente, como lo veremos, hará falta poner en su sitio cierto número de criterios operativos que permitan atestiguar objetivamente que tal sujeto es una persona hecha y derecha: en efecto, en tanto que persona, es sujeto de derecho, provisto de dignidad, y el respeto a dicha dignidad prohibe considerarla como una simple cosa. Los criterios que permiten certificar que una substancia corporal dada es una persona hecha y derecha corresponden a las performances empíricamente constatables.

La tesis lockeana, que define a la persona por sus performances y no por su substancia, levanta un primer problema: ¿cómo explicar la transferencia de contenido de la conciencia de una substancia a otra? El filósofo inglés está consciente de tal dificultad, pero, para gran sorpresa del lector, no propone argumento alguno que demuestre que dicha transferencia sea real o, al menos, concebible racionalmente. Se contenta con decir que la realidad de una transferencia tal debería ser demostrable por la razón si se prueba que la consecuencia de la transferencia-la presencia de una persona en dos substancias pensantes-es realmente posible. ${ }^{79}$

${ }^{78}$ Idem, § 19, 167: "if Socrates and the present Mayor of Quinborough agree, they are the same person", 166 .

${ }^{79}$ Ver idem, $§ 13,155$ : “el problema [la misma substancia pensante ha cambiado: ¿puede así ser la misma persona?] no podría ser resuleto a menos que [...] la conciencia de las acciones pasadas pueda ser transferida de una substancia pensante a otra." ["that cannot be resolved [if the same substance be changed, it can be the same person] [...] whether the consciousness of past actions can be transferred from one thinking substance to another", 154]. "Si la misma conciencia $[\ldots]$ puede pasar de una substancia pensante a otra, entonces será posible para dos substancias pensantes conformar una única persona", 157 ["if the same consciousness [...] can be transferred from one thinking substance, it will be possible, that two thinking substances may make but one person", 156]. 
La antropología lockeana suscita un segundo problema, que fue puesto de manifiesto por sus contemporáneos. Un ser humano profundamente dormido o ebrio no sería, hablando propiamente, una persona, puesto que se encontraría momentáneamente privado de auto-conciencia y de conciencia moral. Si tal ser humano se hiciera matar, no se trataría de un homicidio, pues ninguna persona habría sido asesinada: sólo lo habría sido un ser humano 'despersonalizado'. Por supuesto, Locke condenaría dicho acto en nombre de la religión, que enseña que todos somos hijos de Dios. Pero la razón filosófica no se satisface en absoluto con semejante salto a la trascendencia. Los filósofos bioéticos que reclaman para sí la antropología lockeana lo han percibido con claridad. A fin de resolver esta dificultad, han apelado a la teoría de los intereses: ésta estipula que un individuo debe poder ser capaz de ejercer sus intereses para ser sujeto de derecho. ${ }^{80}$ Matar a un ser humano profundamente dormido ciertamente no iría en contra de un interés en ese preciso momento, si no más bien en contra de un interés de la persona despierta - como estaría si continuara viva- y le causaría así un daño. ${ }^{81}$

Para que este argumento eventualmente sea válido, hace falta que la teoría de la ética de los intereses sea fundada. Dicha ética descansa sobre un a priori aceptado por numerosos filósofos bioéticos, a saber, la tesis del experiencialismo. El experiencialismo sostiene que una acción es buena o mala para un sujeto en la medida en que haga la experiencia. Se puede reprochar a tal ética el ignorar la existencia de intereses propios al ser humano en tanto que ser humano, e independientes del hecho de que sea consciente de sí mismo o de que haya expresado y manifestado un interés por el cual pueda empíricamente constatar la existencia, incluso que esté en condiciones de sentir dolor o placer. Así, por ejemplo, la muerte de un individuo puede ser considerada como un mal para él, inclusive independientemente del hecho de que exista en un "estado de muerte" o de que enfrente la experiencia; independientemente también de su interés actual o pasado, conscientemente expresado, de continuar con vida. El mal que respresenta un aconteci-

${ }^{80}$ Ver, entre otros, Peter Singer, Questions d'éthique pratique, 32ss., 99ss. [21ss. 94ss.].

${ }^{81}$ Ver, por ejemplo, John Harris, The Value of Life, 25ss. 
BERNARD SCHUMACHER

miento no necesariamente procede de la experiencia del dolor. Bien se le puede concebir como en cuanto al orden de la privación de los bienes, de posibilidades y esperanzas que el individuo, naturalmente, pudiera haber podido poseer, realizar y gustar si no hubiese sido proyectado al estado de muerte. El mal de la privación expresa la privación de un bien o de una propiedad denominada personal-como la auto-conciencia o la razón-que un individuo ha ejercido en acto, pero que ya no ejerce, ya no más, o incluso que ya no ejercerá jamás. Por ejemplo, se concibe fácilmente que un mal haya golpeado a un sordo de nacimiento, independientemente del hecho de que sea o no consciente de sí mismo y de que enfrente la experiencia. El mal que representa un estado de cosas no depende forzosamente de la experiencia que un individuo tenga, sino más bien de la privación de un bien debido, es decir, relativo a la naturaleza misma del ser humano. Lo mismo, por ejemplo, en cuanto a la traición, que puede ser considerada como un mal independiente de la experiencia actual o posible que hará un individuo sensible o insensible, consciente de sí mismo o no. ${ }^{82}$

El argumento anticipado por ciertos filósofos bioéticos, a saber, que la ética de los intereses prohibe matar un ser humano en estado de sueño o de ebriedad, no se aplica, sin embargo, para las personas que hubieran expresado conscientemente tal interés. Para los seres humanos que, según la antropología lockeana, no fueran personas todavía-como el embrión o el recién nacido-, o que no podrían serlo jamás -como el individuo que padeciera una discapacidad mental muy grave-, el argumento es caduco. Lógicamente, sería necesario concluir que si se mata a un ser humano que se encuentra en tal situación, es decir, privado de auto-conciencia y de conciencia moral, no se le hace ningún daño. En efecto, ningún interés podría ser contrariado, puesto que no hay ninguno. Inclusive, no habría ni siquiera sujeto que sufra el daño: ninguna persona está presente. John Harris señala, por ejemplo, que "las creaturas que no son capaces ni siquiera de otorgar un valor a su propia existen-

\footnotetext{
${ }^{82}$ Ver Bernard N. Schumacher, Confrontations avec la mort, 193 ss et 211 ss.
} 
cia no pueden sufrir un daño [...] pues su muerte no les priva de cosa alguna a la cual pudieran otorgar un valor. ${ }^{83}$ Y subraya él mismo:

Los seres autónomos y auto-conscientes tienen en un sentido mucho mayor valor, un estatus moral superior que aquellos que viven en el instante sin tener la capacidad de considerarse a sí mismos como seres distintos dotados de un pasado y un futuro. Por ello, los intereses de los seres autónomos y auto-conscientes deben, normalmente, tener prioridad sobre los intereses de todos los demás [...] Afirmar que los seres autoconscientes merecen ser tomados en cuenta prioritariamente es compatible con el principio de la igual consideración de los intereses [...]: algo que ocurra a los seres auto-conscientes puede ser contrario a sus intereses, mientras que sucesos similares no serían contrarios a los intereses de seres que no son auto-conscientes. ${ }^{84}$

Y Jeff McMahan precisa algunos años más tarde en The Ethics of Killing que "ya que tú y yo somos esencialmente espíritus [minds] y que no somos idénticos a nuestros organismos, un recién nacido anencefálico es una clase de cosa fundamentalmente diferente a nosotros. Es simplemente un organismo - un organismo humano permanentemente inocupado". Continúa afirmando sin ambigüedad alguna que "como un recién nacido anencefálico no tiene ni la capacidad ni el potencial para ejercer una conciencia, no es un sujeto de intereses. Nada impor-

${ }^{83}$ "To kill a person not only frustrates their wishes for their own futures, but frustrates every wish a person has. Creatures that cannot value their own existence cannot be wronged in this way, for their death deprives them of nothing they can value." John Harris, The Value of Life, 19. Ver Tristram Engelhardt, The Foundations of Bioethics, 248. Michael Tooley, Abortion and Infanticide, 64. Helga Kuhse y Peter Singer, "Should All Seriously Disabled Infants Live?", Individuals, Humans, Persons. Questions of Life and Death, 1994, Sankt Augustin, Academia Verlag, 159-176, 165.

${ }^{84}$ Peter Singer, Questions d'éthique pratique, 79-80: "It has been suggested that autonomous, self-conscious beings are in some way much more valuable, more morally significant, than beings who live from moment to moment, without the capacity to see themselves as distinct being with a past and a future. Accordingly on this view, the interests of autonomous, selfconscious beings ought normally to take priority over the interests of other beings. [...]The claim that self-conscious beings are entitled to prior consideration is compatible with the principle of equal consideration of interests [...] something that happens to self-conscious beings can be contrary to their interests while similar events would not be contrary to the interests of beings who were not self-conscious." [73]. Ver 96-7 [90-1], 99 [94-5]. 
BERNARD SCHUMACHER

ta, ni es malo o bueno para él. No puede tampoco tener derechos ni ser, en justicia, un objeto de respeto" ${ }^{85} \mathrm{El}$ valor de su existencia dependerá de intereses subjetivos de las personas morales que tengan la responsabilidad. En otras palabras, si este infante anencéfalo quisiera otorgarse un valor, sería de manera extrínseca a lo que él es. El respeto por el ser humano no está fundado, para René Frydman, sino en cuanto "al porvenir del cual es portador". ${ }^{86}$ No tiene derecho a una existencia como persona salvo en la medida en que sea objeto de deseo de sus padres; dicho de otra forma, "un proyecto parental" ${ }^{87}$ En el caso contrario, si no es portador "de ningún proyecto de vida, de ningún deseo parental, para mí es como una cosa". ${ }^{88}$ Tristram Engelhardt, al sostener que el feto o el recién nacido -la afirmación vale igualmente para el individuo con retraso mental profundo- es propiedad de las personas morales o, eventualmente, de una sociedad anónima que lo haya producido, destaca que es "una forma particular de propiedad muy cara". 89 "Ellas [las personas morales] lo han producido, lo han hecho, es suyo". ${ }^{90} \mathrm{Su}$ valor es relativo a los intereses y preferencias de las personas morales. Una 'dignidad' tal es fundamentalmente "relativa". ${ }^{91}$

85 "Since you and I are essentially minds and are not identical with our organisms, an anencephalic infant is a fundamentally different sort of thing from us. It is simply an organism -a permanently unoccupied human organism. [...] Because an anencephalic infant has neither the capacity not the potential for consciousness, it is not a bearer of interests. Nothing can matter, or be good or bad, for its sake. Not can it have rights or be an appropriate object of respect", Jeff McMahan, The Ethics of Killing, 451. "For the killing of a human organism in a PVS [Persistent Vegetative State] is not euthanasia: there is no one there to be benefited by being killing. Not a fortiori, is there anyone there to be harmed." 448.

${ }^{86}$ René Frydman, Dieu, la Médecine et l'Embryon, 1999, 2003, Paris, Odile Jacob, 83. Si bien Frydman habla del embrión, su discurso puede aplicarse a todo ser humano que se encuentre en un estado similar, según los criterios de la persona performante lockeana.

${ }^{87}$ Idem, 84.

${ }^{88}$ Idem, 169.

${ }^{89}$ Tristram Engelhardt, Jr., The Foundations of Bioethics, 255: "a special form of very dear property". "Those who made or procreated the zygote, embryo, or fetus have first claim on making the definitive determination of its value. Privately produced embryos and fetuses are private property. They would be societally owned only if societal groups or cooperatives produced them." 255. Ver 271.

${ }^{90}$ Idem, 255: "They produced it, they made it, it is theirs". Ver 271.

${ }^{91} \mathrm{La}$ introducción de persona social es esencialmente una "construcción utilitarista", Tristram H. Engelhardt, "Medicine and the Concept of Person", 177, y no permite en absoluto otorgar una dignidad intrínseca a los seres humanos despersonalizados. 
Puede preguntarse, con Thomas de Koninck, si el hecho de "reducir al ser humano a lo puramente funcional, al punto de favorecer su eliminación en cuanto no satisface este criterio", criterio que, añadamos, depende de los intereses y preferencias de las personas morales, no es un "acto de barbarie". 92

Un tercer problema concierne al contenido de la memoria, y en particular, a la distinción entre los recuerdos auténticos que tiene una persona realmente, por un lado, y los pseudo-recuerdos que una persona cree tener, pero que son de otra persona o fruto de la imaginación o de la creación, por el otro. La dificultad es la siguiente: ¿se puede demostrar con certeza, moral y jurídicamente, que un pensamiento o una acción particular que ha sido apropiada e imputada por una persona sea auténtica, es decir, que sea realmente suya? ¿Se puede excluir que este pensamiento o acción particular sea en realidad un pseudo-recuerdo, y que realmente nunca haya existido? Lo que está en juego es capital: no se puede juzgar (y consecuentemente recompensar o castigar) a una persona por sus acciones pasadas, salvo si estamos en presencia de la misma persona que aquella que ha realizado dichos actos. Se llega, en efecto, a que subjetivamente consideramos auténticos algunos pseudorecuerdos de nosotros mismos, cuyo contenido jamás ha existido en la realidad. Hemos creado dicho contendido con la ayuda de nuestra imaginación, consciente o inconscientemente y por razones diversas, por ejemplo, si nos fue contado por algún familiar o por nuestros íntimos, cuando jamás hemos hecho la experiencia. De la misma manera, pensemos en un paciente de un asilo psiquiátrico que se toma por Sócrates: con auténtica subjetividad, tal vez con inconsciente mala fe o incluso con mala fe consciente, pero imperceptible para un tercero, pretende acordarse de un pensamiento o acción del filósofo ateniense. ¿Cómo no mencionar aquí el principio de la primera meditación metafísica de René Descartes y el montaje de la duda metódica, cuyo principio consiste en rechazar toda opinión a la menor provocación de duda? Después de haber puesto en duda la realidad de los objetos percibidos por los cinco sentidos, debido a que éstos serían engañosos de vez en vez, el filósofo francés

${ }^{92}$ Thomas de Koninck, De la dignité humaine, 11. 
BERNARD SCHUMACHER

asevera que ciertamente no es posible dudar, en un primer momento, de que:

Estoy aquí, sentado frente al fuego, vestido con una bata, sosteniendo este papel entre las manos y otras cosas de esta naturaleza. ¿Y cómo podría negar que estas manos y este cuerpo son míos? Tal vez, si me comparo con esos insensatos, cuyo cerebro está de tal manera turbado y ofuscado por los negros vapores de la bilis, que aseguran constantemente que son reyes, cuando son muy pobres; que están vestidos de oro y púrpura, cuando están totalmente desnudos; o que se imaginan ser cántaros o tener el cuerpo de vidrio. ¿Pero qué? Son locos; y yo no sería menos extravagante si me rigiera por sus ejemplos. ${ }^{93}$

Es igualmente posible, en un sueño, experimentar subjetivamente el hecho de percibir las acciones o los pensamientos como auténticos. Esta problemática ha sido ilustrada por el cine: pienso en la entrevista de Neo y Morpheus en el cuarto 1313 del hotel Lafayette, escena de la película Matrix de los hermanos Wachowski (1999), ${ }^{94}$ o incluso en Awaking Life de Richard Linklater (2001), que recuerda la idea desarrollada por Platón con la ayuda de su mito de la caverna, ${ }^{95}$ o por René Descartes en sus Meditaciones metafísicas. El reto consiste en encontrar las pruebas racionales de que yo no me encuentro dentro de un sueño, y en particular, que los recuerdos que tengo son reales. Se trata, en otros términos, de distinguir un estado de autosugestión y de locura de un estado real.

Uno de los problemas centrales de la definción "desubstancializada" de la persona en Locke reside en la dificultad de rendir cuentas por medio de la razón, de manera que se trascienda la subjetividad, de la certeza subjetiva de ser una misma persona a través del tiempo; dicho de otra manera, de fundar objetivamente dicha certeza. Así, ¿puede Nicolás proporcionar una prueba diferente a su convicción subjetiva

${ }^{93}$ René Descartes, Méditations métaphysiques, $1{ }^{\text {ère }}$ méditation, 27-8.

${ }^{94}$ Ver Larry y Andy Wachowski, The Matrix. The Shooting Script, 2001, New York, Newmarket Press, 26ss.

${ }^{95}$ Voir Platon, La République, 2004, Paris, Garnier Flammarion, trad. de Georges Leroux, libro VII, 514a-517a, 358-62. 
para demostrar a la comunidad de personas morales que él mismo y Sócrates son la misma persona, hecha y derecha, que ha tenido tal pensamiento y llevado a cabo tal acción en Atenas? Consciente del problema que plantea la distinción entre los recuerdos auténticos y los falsos, Locke reconoce la dificultad de "concluir de la naturaleza de las cosas que una sola y única substancia intelectual no se puede representar como hecho propio lo que jamás ha hecho, si no que tal vez otro agente lo haya realizado". ${ }^{96}$ Sin embargo, incluso reconociendo la amplitud de la dificultad, el filósofo inglés no propone-de nuevo, para sorpresa del lector- ningún medio racional para trascender la convicción subjetivamente auténtica de haber tenido tal pensamiento o de haber hecho tal acción, a fin de verificar en los hechos el contenido de la certeza subjetiva. Para salir del paso, ha recurrido -justo como René Descartes- a la afirmación de un Dios bueno, cuya existencia levanta sus ojos al orden de la fe. En efecto, sólo la creencia en un Dios bueno y justo permite a Nicolás saber que no será recompensado o condenado por un pensamiento o acción que él subjetivamente creía haber tenido o realizado, cuando en realidad algún otro la hubo tenido o realizado, o que simplemente no habría existido jamás. ${ }^{97}$ La fe en la bondad divina garantiza no sólamente la justicia del juicio final, sino también la certeza de la identidad personal a través del tiempo. Como veremos, el filósofo inglés emplea un tipo de argumento similar, es decir, no filosófico, en el caso particular del juicio de una acción de la cual la persona no tiene recuerdo alguno.

Una cuarta dificultad estriba en que, para resolver un problema central de su definción de persona, se refugia tras lo que considera como un acto de fe en la existencia de un Dios cristiano, bueno y justo. Intenta llenar un déficit mayor de su antropología al mutar en teólogo cristiano, lo que en definitiva, termina por no probar nada en absoluto. Un argumento tal vale sin duda para las personas y para la comunidad que comparte una fe; pero pierde todo su peso en el contexto de una sociedad laica y secu-

${ }^{96}$ John Locke, "Identité et différence", § 13, 157: "why one intellectual substance may not have represented to it, as done by it self, what it never did, and was perhaps done by some other agent, why I say such a representation may not possibly be without reality of matter of fact."

${ }^{97}$ Ver John Locke, idem, § 13, 157. 
BERNARD SCHUMACHER

larizada, compuesta por personas que tienen diferentes concepciones del mundo. La definción de persona dada por Locke, que se basa únicamente en la auto-conciencia subjetiva y en conciencia moral, rechazando la substancia corporal como parte constitutiva e individualizante de la persona, a fin de cuentas prueba estar desprovista de fundamento racional. El único criterio que permite verificar la identidad de la persona, a saber, la certeza subjetiva de la conciencia, se revela aleatoria e insuficiente: nos encontramos en presencia de una posición subjetivista y relativista. La respuesta del filósofo inglés, tanto más extraña cuanto que desarrolla una concepción de la razón que se opone a la autoridad, sostiene, como explica Charles Taylor, que un conocimiento "no es auténtico a menos que lo desarrollemos nosotros mismos". ${ }^{98}$ Locke mismo afirma: "en cuanto a las cosas que cree y recibe simplemente a partir de la fe de otro [...] no son sino jirones". ${ }^{99}$ Se podría aplicar esta descripción a la antropología lockeana.

\section{La persona moral social como término jurídico}

La antropología lockeana de la persona se interesa principalmente en el ejercicio de acciones y considera, así, como sujeto moral a la persona. Libre y dotada de inteligencia, la persona está en capacidad de obrar según las leyes morales, las cuales están inscritas en su naturaleza, fundadas en Dios, erigidas por la razón universal o por la razón subjetiva. Se distingue, por otra parte, por una cierta inquietud frente a la posibilidad de no dar cumplimiento a su existencia como consecuencia de actos morales libres. Dicho en otra forma, se caracteriza por "el cuidado de su propia felicidad" 100 por parte de su actividad anticipadora. Locke reconoce, ciertamente, que la persona siente placer

${ }^{98}$ Charles Talyor, Les sources du moi. La formation de l'identité moderne, 1998, Paris, Seuil, 221 [Sources of the Self. The Making of the Modern Identity, 1989, Cambridge, Harvard University Press: "Knowledge for Locke isn't genuine unless you develop it yourself", 167].

${ }^{99}$ John Locke, Essai philosophique concernant l'entendement humain, libro I, capítulo $3, \S 23,57$ : "What he believes only, and takes upon trust, are but shreads", cap. 4, § 23, 101.

${ }^{100}$ John Locke, "Identité et différence", § 26, 177: "All which is founded in a concern for happiness", 176. 
y dolor a semejanza del ser humano (en sentido biológico) y del animal, pero se diferencia por su capacidad de ser "consciente del placer y del dolor". ${ }^{101}$ Esta tesis será retomada por un buen número de especialistas en bioética, señaladamente por Peter Singer, autor de una teoría ética de la igual consideración de los intereses y que sostiene que ciertos animales serían personas. ${ }^{102}$ Así, sólo la persona puede cuidarse a sí misma en el futuro, pues sólo ella puede trascender la inmediatez y proyectarse como el mismo yo en un porvenir más o menos lejano. Peter Singer invoca la misma razón cuando afirma que el ser humano racional y auto-consciente - la persona- posee "las capacidades mentales que le harán, en ciertas circunstancias, llegar a sufrir más que los animales lo harían en las mismas circunstancias". ${ }^{103}$

En efecto, la persona percibe el sufrimiento de manera más aguda, pues, consciente de que su identidad personal está inscrita en el tiempo, puede proyectarse hacia un porvenir, temer un acontecimiento futuro nefasto. El ejercicio de este cuidado de su felicidad como criterio de presencia de una persona, criterio por otra parte recientemente defendido por John Harris, ${ }^{104}$ está íntimamente ligado, según Locke, al hecho de que el yo debe rendir cuenta de sus acciones delante del tribunal de la Ciudad y, en fin, delante del tribunal de Dios. Para que las acciones libres personales puedan ser recompensadas o culpadas, deben ser imputadas a un mismo yo existente a través del tiempo y que

${ }^{101}$ Idem, § 26, 177: “conscious of pleasure and pain", 176.

${ }^{102}$ Ver Peter Singer, Questions d'éthique pratique, 114-21 [111-9]. Ver también Bernard N. Schumacher, Confrontations avec la mort, 54ss., donde desarrollo, en referencia a cierto número de estudios etológicos, la tesis según la cual el animal no tiene la capacidad de ser consciente de su propia mortalidad, pues no es auto-consciente, ni tampoco la capacidad de proyectarse en un futuro.

${ }^{103}$ Peter Singer, op. cit., 67: "mental capacities that will, in certain circumstances, lead them to suffer more than animals would in the same circumstances", 59.

104 "A person will be any being capable of valuing its own existence. [...] On this concept of the person, the moral difference between persons and non-persons lies in the value that people give to their own lives. The reasons it is wrong to kill a person is that to do so robs that individual of something they value, and of the very thing that makes possible valuing anything at all. To kill a person not only frustrates their wishes for their own futures, but frustrates every wish a person has. Creatures that cannot value their own existence cannot be wronged in this way, for their death deprives them of nothing they can value", John Harris, The Value of Life, 1985, London, Routlegde/Kegan Paul, 18-9. 
BERNARD SCHUMACHER

puede responder por sus acciones. En el caso contrario, el juicio sería injusto, pues recompensaría o culparía a una persona por una acción que otra persona habría realizado, como hemos visto anteriormente. La justicia del juicio implica, necesariamente, una continuidad de la persona entre el instante del juicio en $\mathrm{T} 2 \mathrm{y}$ el del acto moral realizado en el pasado en $\mathrm{T} 1$.

Locke desarrolla una concepción de la persona limitada al plano jurídico: la persona es, antes que nada, un "término jurídico". ${ }^{105}$ Por ello, es necesario que el sujeto ejerza una auto-conciencia y una conciencia moral con la ayuda de la memoria de sus pensamientos o acciones pasadas. La persona es:

Un término del lenguaje jurídico que se asigna la propiedad de sus acciones y de su mérito, y como tal, pertenece sólo a los agentes dotados de inteligencia, susceptibles de reconocer la ley y de sentir felicidad y miseria. ${ }^{106}$

De esta manera, Locke aplica un cambio antropológico radical, al reducir la definición de persona a la esfera jurídica y social de la comunidad moral. Sólo los seres humanos en condiciones de realizar acciones morales son considerados como personas, propiamente hablando. Para ello, deben estar en condiciones de ejercer la auto-conciencia y la conciencia moral: "sin conciencia", precisa el filósofo inglés, "no hay persona", ${ }^{107}$ es decir, persona social jurídica. Buen número de filósofos bioéticos asumen esta afirmación al sostener que sólo un individuo moral está en condiciones de formular racionalmente sus intereses en cuanto a los derechos -en particular, el derecho a la vida.

En este contexto, Locke se preguntaría si Nicolás debería ser condenado en un tribunal por una acción moral estimada como mala por la comunidad y cometida en T1, mientras se encontraba ebrio o sonámbulo. El problema es que, en T2, éste no recuerda nada de la acción

${ }^{105}$ John Locke, "Identité et différence", § 26, 177: "Person a forensic term", 176.

${ }^{106} \mathrm{Idem}, \S 26,177$ : "It [Person] is a forensic term appropriating actions and their merit; and so belongs only to intelligent agents capable of law, and happiness and misery", 176.

${ }^{107}$ Idem, $\S 23,171$ : "For whatever substance there is, however framed, without consciousness, there is no person", 170. 
realizada. Lógicamente, Locke debería sostener que Nicolás no debe ser condenado, dado que nos estamos ocupando de dos personas distintas en T1 y T2, pues en T2 la persona afirma que no se imputa la acción realizada en T1. Al declararla culpable, cometeríamos una grave falta de juicio, ya que condenaríamos a una persona por una acción que jamás ha llevado a cabo. ¿Cuál es la posición del filósofo inglés frente a una situación así, tomada de la cotidianeidad? Mantiene que, si un tribunal debe castigar a una persona despierta o sobria por una acción moral realizada en estado de ebriedad o de sueño profundo, lo haría "justamente". 108

¿Qué es lo que le permite albergar dicho propósito? La razón invocada se sitúa sobre el plano de la prueba y, más particularmente, de su credibilidad. El juez o el jurado tiene delante de sí 'pruebas': por una parte, la de la persona sobria que niega la acción pasada; por el otro, la de la acción de la persona ebria que ha sido vista por testigos. El tribunal elige, con justicia, "la prueba del hecho" (que exige también, dicho sea de paso, en el caso de la cuasi-memoria o en el de la negativa a imputarse acciones pasadas por mala fe, consciente o inconsciente). Nuestro filósofo desacredita así la afirmación de la persona sobria, cuando le otorga toda su confianza, como lo hemos visto, si aquella debiera sostener que era Sócrates. ¿Cuál es la razón esgrimida? El juez o el jurado se apoya sobre lo que puede conocer para llevar a cabo un juicio sobre la responsabilidad de acciones morales del individuo ebrio. Al no poder penetrar en el seno de la conciencia de la persona sobria, a fin de controlar si verdaderamente no recuerda la acción pasada, ni distinguir con certeza una actitud de veracidad de una actitud de fingimiento o engaño, el juez o el jurado se ven obligados -si el deseo es no cometer una injusticia- a juzgar a partir de los elementos disponibles.

¿Cuáles son, entonces, los criterios utilizados para conseguir dicho juicio? Asombrosamente, Locke deja de lado la conciencia personal subjetiva y emplea la substancia corporal del ser humano como prueba de que se trata de la misma persona en dos momentos diferentes. Para condenar con justica a la persona en T2, el juez o el jurado deben

${ }^{108}$ Idem, § 22, 171: “justly”, 170. 
BERNARD SCHUMACHER

suponer que hay identidad entre ella y el ser humano ebrio en T1. Esto no es posible, sino en referencia a una substancia corporal particular; Locke la reintegra, súbitamente, al seno de la definción de persona. Así, juez ni jurado se verán obligados de probar la presencia de dos personas distintas, es decir, la persona ebria en T1 y la persona sobria en T2, sino que el peso de la prueba en función de la acción moral realizada en T1 descansa sobre la persona sobria en T2, que debe probar su inocencia. ${ }^{109}$

La antropología lockeana hace uso de un doble criterio para identificar a la persona. Al poner entre paréntesis toda referencia a una substancia corporal que identifica al ser humano biológico, el filósofo inglés sostiene, de inicio, que el criterio de identificación de la misma persona está constituido por esta misma persona en su interioridad, sin que pueda estar fundado por una instancia externa. Su identidad no es accesible salvo a ella misma, en la medida en que la autoconciencia se caracteriza por una cierta autenticidad contraria a ella misma; dicho de otra forma, donde la mala fe no puede alojarse. Resulta que nadie, sino Nicolás, está en condiciones de afirmar si la apropiación e imputación de acciones o pensamientos son verídicas o falsas. Locke declara enseguida que el criterio de identificación de la persona es la substancia corporal particular, que pertenece al orden 'de los hechos', es decir, empíricamente cosntatable y objetivo. La existencia personal en el seno de la comunidad humana no depende ya de la conciencia subjetiva y de su capacidad de apropiarse e imputarse actos o pensamientos pasados con la ayuda de la memoria. La prueba del 'hecho'-la referencia a la substancia corporal particular- es suficiente para determinar la presencia de una misma persona.

A fin de distinguir la verdad de la ficción en el caso arriba expuesto (justo como el del alcalde de Quinborough que se cree Sócrates) y de sostener la justicia del veredicto que condena a Nicolás por actos realizados en estado de ebriedad o sonambulismo, Locke se ve obli-

${ }^{109} \mathrm{El}$ hecho de que el tribunal no condene, por ejemplo, a una persona por una acción singular durante un estado de sueño profundo, no significa que otra persona haya realizado dicha acción, sino que ella no pudo ser responsable de la acción en disputa, pues no era consciente al momento del hecho. 
gado, a pesar suyo podría decirse, a trascender el solipsismo de la auto-conciencia y de introducir en su definción de persona un fenómeno observable por otro: la substancia corporal particular. La distinción entre 'ser humano' y 'persona' de esta manera se vuelve caduca. La presencia de una substancia corporal particular empíricamente constatable basta para revelar la identidad de la persona, la cual no se deja reducir al ejercicio empíricamente verificable de su auto-conciencia y de su conciencia moral. Un ser humano incapaz de ejercer su conciencia, puntualmente o de forma definitiva, merecería el estatus de persona tanto como un ser humano destacado en tal ejercicio. La posición que Locke defiende en el caso del veredicto implica una identificación entre ser humano y persona; lo anterior equivale a decir que un embrión, un recién nacido o un adulto que sufra una discapacidad mental muy grave, o que esté sumido en cualquier otro estado similar, no se distinguiría en nada de un filósofo en cuanto a su estatus de persona. El hecho de "escribir o leer libros de filosofía", ${ }^{110}$ que según Tristram Engelhardt es lo propio de las personas, no es ya esencial para ser persona. Constitutivo de la persona humana, "todo cuerpo humano, sea cual fuere-demente profundo, Einstein, comatoso, tres veces campeón olímpico-, merece, precisa Thomas de Koninck, el mismo respeto". ${ }^{111}$ Aunque tengan la misma dignidad, dichas personas se diferencian, no obstante, por el grado de cumplimiento de su humanidad, que depende, entre otras cosas, del ejercicio de la conciencia moral y del juicio.

Puesto que Locke recurre al 'hecho' de la substancia corporal para reconocer la inocencia o culpabilidad de una persona que obra en estado de ebriedad o sueño profundo, deberá aplicar este mismo razonamiento a todos los casos en que la persona no recuerde sus acciones pasadas, por ejemplo, el de la persona profundamente demente. Lógicamente, Locke debería sostener -lo cual no hace en absoluto- que, a pesar del hecho de que la persona adulta auto-consciente no recuerde ninguna de sus acciones o pensamientos pasados, es la misma persona; en efecto, de manera analógica al argumento adelantado por el tribunal, las personas contemporáneas de tal época pasada-su familia, etc.- atesti-

${ }^{110}$ Engelhardt, The Foundations of Bioethics, 136: "Only persons write or read books on philosophy".

${ }^{111}$ Thomas de Koninck, De la dignité humaine, 98. 
BERNARD SCHUMACHER

guan que se trata, totalmente, de la misma persona. Lo hacen al referirse, por un lado, a su memoria, que les recuerda cierto número de hechos que les conciernen, tales como, por ejemplo, su nacimiento. $\mathrm{O}$, según la antropología de la persona performante, dicha memoria permite afirmar a los padres únicamente su propia identidad a través del tiempo. La memoria es incapaz de constituir al prójimo como persona en sí. Lo que sí puede hacer, es crear al prójimo como persona ficticia con la ayuda de la imaginación. Su familia la identifica, sin embargo, como una sola y misma persona al referirse, por otro lado, al 'hecho' de su substancia corporal particular, que puede ser verificada en el plano biológico. A pesar de la ausencia de todo recuerdo, se puede atribuir a ese período una vida personal idéntica, al basarse en el testimonio del prójimo y, más fundamental, al referirse a la identidad biológica del cuerpo que la constituye.

La experiencia empírica que identifica una misma persona con la ayuda de una misma substancia corporal descrita en el caso del juicio se opone a la definición de persona desarrollada en la primera parte, que sostiene que dos personas pueden encontrarse en un mismo cuerpo. Si esta última definción fuera verdadera, como Locke sostiene, sería profundamente injusto descansar sobre el criterio de la corporeidad para identificar a una persona; ésta no puede ser identificada más que por el sujeto mismo. Consciente de la dificultad de juzgar con justicia, Locke se apresura a proponer -como lo hizo con el problema de los falsos recuerdos- un argumento teológico: afirma que en el Juicio final la conciencia personal se vuelve completamente transparente, lo cual excluye toda posibilidad de pseudo-recuerdos y de mala fe, pues lleva ahora, en ella misma, un juicio plenamente objetivo.

Pero en el Gran Día, cuando los secretos de todos los corazones serán puestos al desnudo, razonablemente se puede pensar que nadie será forzado a responder de lo que nada conoce, sino que recibirá el veredicto: su conciencia acusándolo o excusándolo. ${ }^{112}$

${ }^{112}$ John Locke, "Identité et différence", § 22, 171: "But in the Great Day, wherein the secrets of all hearts shall be laid open, it may be reasonable to think, no one shall be made to answer for what he knows nothing of; but shall receive his doom, his conscience accusing or excusing him”, 170. Ver $\S 26,179$ [178]. 
Un razonamiento teológico tal, con miras a resolver las dificultades de su posición antropológica, es ciertamente comprensible en el contexto histórico, en el sentido de que el juicio divino formaba parte de las ideas comúnmente aceptadas en esa época. Empero, la situación en Occidente ha cambiado: el juicio divino no forma parte de las creencias generalmente admitidas. Se trata más bien de una creencia compartida por algunos fieles; dicho de otra forma, por una comunidad que comparte la misma concepción del mundo que Engelhardt denomina "amigos morales". ${ }^{113}$ Puesto que el recurso de Locke tiene una trascendencia de fe, se encuentra privado de todo peso argumentativo. Se desprende el siguiente problema: sea mantener que la persona es una auto-conciencia y una conciencia moral sin substancia y solipsista, y que se debe calificar de injusto al juicio pronunciado con ayuda de la identidad corporal biológica, aceptando así la imposibilidad de fundar una ética de la justicia; sea sostener que la corporeidad es parte constitutiva de la persona, restituyendo la posibilidad de un juicio justo de las acciones realizadas por la misma persona.

\section{Conclusión}

Los filósofos bioéticos contemporáneos que asumen la antropología lockeana de la persona buscan resolver algunos problemas delicados que tocan la vida y la muerte. Para hacerlo, la definción de persona es crucial. Si, en un momento dado, un ser humano es privado de manera irreversible de su auto-conciencia y de su conciencia moral performante, no será -según la antropología lockeana- una persona. Como lo subraya Michael Tooley, "si el feto no es una persona [y podría añadirse, todo ser humano que no sea persona según la acepción lockeana], ¿cómo podría ser seriamente incorrecto destruirlo?" 114 Si bien Locke no se preocupa en absoluto de cuestiones relativas a la vida y a la muerte, no obstante, no queda sin equívoco su concepción de persona. Para

${ }^{113}$ Ver Engelhardt, op. cit., 7.

114 "If the foetus is not a person, how can it be seriously wrong to destroy it?", Michael Tooley, "Abortion and Infanticide", 39. 
BERNARD SCHUMACHER

comenzar, afirma que "sin conciencia no hay persona", ${ }^{115}$ y enseguida que el estatus de persona "no pertenece sino a agentes dotados de inteligencia, susceptibles de reconocer una ley y de experimentar felicidad y miseria". ${ }^{116}$ La antropología lockeana se caracteriza, así, por tres elementos.

En un primer tiempo, la persona se caracteriza exclusivamente por el ejercicio de la auto-conciencia. En esta óptica, la certeza de ser el mismo yo a través del tiempo está anclada en la subjetividad solipsista: cada conciencia está encerrada "en su propio asilo mental privado". ${ }^{117} \mathrm{Al}$ calificar justamente a la antropología lockeana de "concepción radicalmente subjetivista de la persona", ${ }^{118}$ Charles Taylor precisa que este "yo puntual devinculado" se caracteriza por "una pura conciencia independiente", ${ }^{119}$ desvinculada de la substancia corporal singular. En adelante, el cuerpo humano particular es percibido como un objeto cualquiera, mecánico y funcional: Thomas de Koninck llama a esto "desencantamiento" del cuerpo, ${ }^{120}$ pues éste no tiene ya dignidad. Lo observamos bajo la pluma de numerosos filósofos bioéticos, que sostienen que un cuerpo humano vivo desprovisto del ejercicio de la auto-conciencia y de la conciencia moral es asimilable a una cosa desprovista de dignidad. ${ }^{121}$

En segundo lugar, la antropología lockeana se caracteriza por una reducción de la persona a su dimensión moral. Para ser una persona, es necesario estar en capacidad de experimentar la felicidad y la mise-

${ }^{115}$ John Locke, "Identité et différence", § 23, 171: "without consciousness, there is no person: and a carcase may be a person", 170.

${ }^{116} \mathrm{Idem}, \S 26,177$ : "belongs only to intelligent agents capable of law, and happiness and misery", 176.

${ }^{117}$ Fergus Kerr, La théologie après Wittgenstein, 118: "locks each mind into its own private mental asylum", 82. La describe igualmente como "la imagen del yo solitario, comunicado consigo mismo, radicalmente independiente de relación alguna con alguien más en el mundo" 104. ["This picture of the solitary self-communing self, radically independent of relationships with anyone else in this world", 72].

${ }^{118}$ Charles Taylor, Les sources $d u$ moi, 227: "This radically subjectivist view of the person", 172.

${ }^{119}$ Idem, 228: "pure independent consciousness", 172. 211: "Punctual Self [...] disengaged", 159.

${ }^{120}$ Thomas de Koninck, De la dignité humaine, 87. Ver 95.

${ }^{121}$ Ver, por ejemplo, Jeff McMahan, The Ethics of Killing, 451. 
ria, de tener cuidado por la propia felicidad en un porvenir incierto $y$ de proyectarse en el futuro como un mismo yo.

En un tercer momento, Locke introduce una calificación antropológica suplementaria, al presentar la persona, como un "agente moral que asume la responsabilidad de sus actos a la luz de sanciones futuras", para retomar una expresión de Charles Taylor. ${ }^{122}$ La persona se define por su dimensión social y jurídica, lo que presupone que sea consciente de sí misma y que obre moralmente.

Esta reducción de la persona a sujeto que comparece en un tribunal está conforme a la tesis - dada a priori-de que sólo lo que es empíricamente constatable - en nuesto caso preciso, el ejercicio de la auto-conciencia y de la conciencia moral- tiene valor moral. Dicha tesis constituye uno de los fundamentos de una de las corriente bioéticas contemporáneas: sólo el ejercicio y el dominio de las accciones definen a un ser. En otros términos, para ser persona es necesario ejercer la autoconciencia y la conciencia moral; para ser sujeto de derecho y, más específicamente, para el derecho a la vida, es necesario ejercer intereses. Resulta que, los seres humanos que no están en condiciones de establecer empíricamente que ejercen un interés tal en vivir, no tienen intereses ni, por tanto, derechos. No tienen derechos, precisan ciertos filósofos bioéticos, a menos que la comunidad de personas decida otorgárselos por procuración, lo que quiere decir que tales derechos son, en un último análisis, relativos a los intereses de las personas. Lo mismo en el caso de los seres humanos que, por diversas razones, son desgraciadamente incapaces de ejercer su auto-conciencia y su conciencia moral: Locke cita al embrión humano y al loco privado de racionalidad, ${ }^{123}$ que no tendrían "más razón que un gato o un periquito". ${ }^{124}$ Según su antropología de la performance, sencillamente no son considerados como personas ni como sujetos de derecho en sentido jurídico.

${ }^{122}$ Charles Taylor, op. cit., 228: "the moral agent who takes responsibility for his acts in the light of future retribution", 173.

${ }^{123}$ Lo hace en el pasaje en que trata sobre la identidad del ser humano, en el cual se pregunta si son seres humanos: John Locke, "Identité et différence", § 6, 143 [142].

${ }^{124}$ Idem, $\S 8,145$ : "though it had no more reason all its life, than a cat or a parrot", 144. 
BERNARD SCHUMACHER

Exigir tal performance es, a mi juicio, erróneo, pues la razón permite afirmar la existencia de intereses, independientemente del hecho de que el sujeto los exprese, a saber, intereses intrínsecos y constitutivos del sujeto. Por otro lado, el funcionamiento empírico de la conciencia -condición absoluta para obtener el estatus de persona según la antropología lockeana- en realidad no es sino la expresión verificable de la constitución ontológica de la persona, que permite el despliegue de la performance. Existe confusión entre lo que es del orden del acto de una res, a saber, su capacidad ontológica o radical que le es constitutiva, y lo que es del orden de la performance de dicha res, a saber, la capacidad actual de ejercer las propiedades llamadas personales. La antropología performante lockeana identifica falsamente la persona con un yo que es empíricamente observable por la performance de sus propiedades personales. Esto no es así, porque la base neurofisiológica no permite ya la manifestación empírica del ejercicio de la auto-conciencia ni de la conciencia moral, lo cual lleva a concluir que no hay ya persona. La privación momentánea y, sobre todo, irreversible del ejercicio de la conciencia no implica la no-presencia de la persona.

De lo anterior se desprende que uno de los desafíos fundamentales de la reflexión bioética contemporánea reside en la liberalización de la noción de persona, a fin de pasar de la esfera ética y jurídica a la esfera de su fundamento ontológico. Para hacerlo, es necesario volver a investir a la persona de su corporeidad constitutiva, como por otro lado, hizo Locke al dar la razón al jurado que ha tomado en cuenta la corporeidad para la identificación de la persona. La mayor parte de los filósofos bioéticos que distinguen al ser humano de la persona -aparentemente molestos con las consecuencias éticas de dicha distinciónproponen otorgar algunos derechos a ciertos organismos humanos juzgados no personales, debido a que han sido personas, o que es necesario considerarlos, al menos, como si fueran personas. Estas tomas de postura intelectual presentan numerosas fallas argumentativas. Dichos filósofos proponen otorgar a los organismos mencionados una dignidad por procuración, bajo reserva de los intereses y de las preferencias de terceras personas. Así, tal dignidad es "relativa": un organismo humano que no 
fuera, propiamente hablando, una persona, y que no presentara ningún interés por sus prójimos, estaría a merced de su voluntad. Dichas afirmaciones son profundamente contra-intuitivas pues, en nombre de una antropología denominada performante, desembocan en una 'legitimidad' ética de la instrumentalización: posibilidad de la eliminación de seres humanos no-performantes y no funcionales para sus pares. ${ }^{125}$

${ }^{125}$ Agradezco a mi esposa Michele sus muy pertinentes observaciones, así como a Nicolás de Araujo sus correcciones estilísticas al francés. 
La reproducción total o parcial de este artículo se podrá hacer si el ITAM otorga la autorización previamente por escrito. 